\title{
A Core Paired-Type and POU Homeodomain-Containing Transcription Factor Program Drives Retinal Bipolar Cell Gene Expression
}

\author{
Douglas S. Kim, ${ }^{1}$ Takahiko Matsuda, ${ }^{1}$ and Constance L. Cepko ${ }^{1,2}$ \\ ${ }^{1}$ Department of Genetics and ${ }^{2}$ Howard Hughes Medical Institute, Harvard Medical School, Boston, Massachusetts 02115
}

\begin{abstract}
The diversity of cell types found within the vertebrate CNS arises in part from action of complex transcriptional programs. In the retina, the programs driving diversification of various cell types have not been completely elucidated. To investigate gene regulatory networks that underlie formation and function of one retinal circuit component, the bipolar cell, transcriptional regulation of three bipolar cell-enriched genes was analyzed. Using in vivo retinal DNA transfection and reporter gene constructs, a $200 \mathrm{bp}$ Grm6 enhancer sequence, a $445 \mathrm{bp}$ Cabp 5 promoter sequence, and a 164 bp Chx 10 enhancer sequence, were defined, each driving reporter expression specifically in distinct but overlapping bipolar cell subtypes. Bioinformatic analysis of sequences revealed the presence of potential paired-type and POU homeodomain-containing transcription factor binding sites, which were shown to be critical for reporter expression through deletion studies. The paired-type homeodomain transcription factors (TFs) Crx and Otx2 and the POU homeodomain factor Brn2 are expressed in bipolar cells and interacted with the predicted binding sequences as assessed by electrophoretic mobility shift assay. Grm6, Cabp5, and Chx10 reporter activity was reduced in Otx2 loss-of-function retinas. Endogenous gene expression of bipolar cell molecular markers was also dependent on paired-type homeodomain-containing TFs, as assessed by RNA in situ hybridization and reverse transcription-PCR in mutant retinas. Cabp5 and Chx10 reporter expression was reduced in dominant-negative Brn2-transfected retinas. The paired-type and POU homeodomain-containing TFs Otx2 and Brn2 together appear to play a common role in regulating gene expression in retinal bipolar cells.
\end{abstract}

Key words: retina; bipolar cells; transcription factor; metabotropic glutamate receptor 6; calcium-binding protein 5; Chx10

\section{Introduction}

Retinal function is carried out by diverse cell types that exhibit distinct morphology, connectivity, and physiology. The diversity of retinal cell types is also evident in the considerable gene expression heterogeneity observed in developing and mature retinal cells (Blackshaw et al., 2004; Gray et al., 2004; Trimarchi et al., 2007, 2008). The mechanisms underlying molecular diversity of retinal cells could be further revealed by examining transcriptional programs that orchestrate gene expression in specific cell types. In this study, the regulation of gene expression in retinal bipolar cells was investigated. Bipolar cells are the first relay interneurons in the visual system. They connect rod and cone photoreceptor cells to amacrine and ganglion cells and are critical in processing and routing visual signals. Bipolar cells express unique

\footnotetext{
Received Jan. 29, 2008; revised May 28, 2008; accepted June 16, 2008.

D.S.K. was supported by National Institutes of Health (NIH) Grants F32 EY15360 and T32 EY007145. C.L.C. was supported by NIH Grant R01 EY009676 and the Howard Hughes Medical Institute. We gratefully acknowledge M. Emerson and J. Trimarchi for a critical reading of this manuscript.

D.S.K, T.M., C.L.C., and Harvard University have submitted a patent application for the use of the Grm6, Cabp5, and $C h \times 10$ regulatory elements described in this publication and thus declare a competing financial interest.

This article is freely available online through the J Neurosci Open Choice option.

Correspondence should be addressed to Constance L. Cepko, Howard Hughes Medical Institute, Department of Genetics, Harvard Medical School, 77 Avenue Louis Pasteur, Boston, MA 02115. E-mail: cepko@genetics. med.harvard.edu.

DOI:10.1523/JNEUROSCI.0397-08.2008

Copyright $\odot 2008$ Society for Neuroscience $\quad 0270-6474 / 08 / 287748-17 \$ 15.00 / 0$
}

combinations of molecules important for form and function (Greferath et al., 1990; Berrebi et al., 1991; Euler and Wässle, 1995; Burmeister et al., 1996; Takebayashi et al., 1997; Vardi and Morigiwa, 1997; Fletcher et al., 1998; Koulen et al., 1998; Vardi, 1998; Baas et al., 2000; Haeseleer et al., 2000; Chow et al., 2001; Ohtoshi et al., 2001; Haverkamp et al., 2003a,b; Huang et al., 2003; Bramblett et al., 2004; Ghosh et al., 2004; Pignatelli and Strettoi, 2004; Kim et al., 2008). However, the transcriptional mechanisms regulating bipolar cell gene expression remain essentially unknown, particularly regarding the signaling molecules, transcription factors (TFs), and genomic cis-regulatory elements (CREs) that direct specific gene expression patterns.

Previous studies have examined retinal phenotypes resulting from mutation of TF genes expressed within bipolar cells and/or their progenitor cells in mice. Several TFs expressed in progenitor cells are required individually or in combination for genesis of bipolar cells in general, including Chx10, Mash1, Math3, and Ngn2 (Burmeister et al., 1996; Tomita et al., 2000; Green et al., 2003; Akagi et al., 2004; Livne-Bar et al., 2006). Other TFs that initiate expression in exiting or postmitotic cells in the developing retina have been shown to play important roles in driving differentiation and/or survival of various types of bipolar cells, including Otx2, Crx, Vsx1, Isl1, Irx5, Bhlhb4, and Bhlhb5 (Bramblett et al., 2004; Chow et al., 2004; Ohtoshi et al., 2004; Cheng et al., 2005; Feng et al., 2006; Clark et al., 2007; Elshatory et al., 
2007). Despite the elucidation of the roles of many individual TFs in bipolar cell development, relationships among TFs and their targets have not been defined.

To examine mechanisms of bipolar cell transcriptional control, the relationship of CREs of several bipolar cell genes and TFs was investigated. CREs for the bipolar cell-enriched and -specific genes, metabotropic glutamate receptor 6 (Grm6), calciumbinding protein 5 (Cabp5), and C. elegans ceh-10 homeodomain containing homolog $(C h \times 10)$, were defined by in vivo retinal transfection of CRE-reporter DNA constructs. TFs regulating these genes were identified using comparative bioinformatic analysis of CRE sequences from different species, biochemical TF binding assays, and examination of reporter and endogenous gene expression in TF loss-of-function retinas. The results reveal that paired-type and POU homeodomain-containing TFs play a common role in regulating bipolar cell gene expression.

\section{Materials and Methods}

Plasmid DNA constructs. The CAG-GFP and UB-GFP plasmids, which contain broadly active promoters that drive green fluorescent protein (GFP) expression, were from Matsuda and Cepko (2004). UB-tdTomato was constructed by excising the tdTomato cDNA from RSET-B-tdTomato (Shaner et al., 2004) and using it to replace the GFP sequence in UB-GFP. The $10 \mathrm{~kb}$ mouse genomic fragment $[-9727$ to +409 relative to the first nucleotide of GenBank accession number BC021919, National Institutes of Health (NIH)] Grm6-LacZ construct was the plasmid $M G 6-Z$, from Ueda et al. (1997). A BglII deletion construct (sequence left in construct: -9727 to -8127 and -2331 to +409 ) was made by BglII restriction enzyme digestion and religation. An $\mathrm{MscI}$ deletion construct (sequence left in construct: -9727 to -7113 and -76 to +409 ) was made by $M s c$ I restriction enzyme digestion and religation. The construct containing the $1 \mathrm{~kb}$ critical region and the $3^{\prime} 0.5 \mathrm{~kb}$ sequence $(-8126$ to -7113 and -76 to +409 ) was made by PCR amplification of genomic sequence from the $M s c \mathrm{I}$ deletion construct using primers 5-GATCTCCAGATGGCTAAAC-3' and 5'-GGCGGACGAAGCTGCCACCC $-3^{\prime}$ and insertion of this fragment into the $L a c Z$ reporter vector. The construct containing the $1 \mathrm{~kb}$ critical region without the conserved $5^{\prime}$ sequence and with the $3^{\prime} 0.5 \mathrm{~kb}$ sequence ( -7946 to -7113 and -76 to +409$)$ was made by PCR amplification of genomic sequence from the $M s c$ deletion construct using primers 5-GGCTCAAACAAGACTGGTTG-3' and 5'-GGCGGACGAAGCTGCCACCC- ${ }^{\prime}$ ' and insertion of this fragment into the $L a c Z$ reporter vector. The construct containing the $0.5 \mathrm{~kb} \mathrm{3}$ ' sequence alone $(-76$ to +409$)$ was made by PCR amplification of genomic sequence from the original $10 \mathrm{~kb}$ construct using primers 5-CCAAGCTTATTGGTGTTGC-3' and 5'-GGCGGACGAAGCTGCCACCC- ${ }^{\prime}$ and insertion of this fragment into the $L a c Z$ reporter vector. The simian virus 40 (SV40) basal promoter-LacZ construct was made by excising the SV40 basal promoter from the GL3 plasmid (Promega) and inserting it into the $L a c Z$ reporter vector. The construct containing the 200 bp region $(-8126$ to -7927$)$ and the SV40 basal promoter was made by PCR amplification of a fragment from mouse genomic DNA using primers 5'-GATCTCCAGATGGCTAAAC- $3^{\prime}$ and $5^{\prime}$-CAACCAGTCTTGTTTGAGCC-3' and insertion of this fragment into the SV40 basal promoter-LacZ vector.

The $4.7 \mathrm{~kb}$ mouse genomic fragment $(-4529$ to +156 relative to the first nucleotide of GenBank accession number NM_013877) from the Cabp5 gene was inserted upstream of GFP or tdTomato by excision from the Cabp5-dsRed plasmid (Matsuda and Cepko, 2004) and insertion into the UB-GFP or UB-tdTomato constructs, replacing the human ubiquitin $\mathrm{C}$ promoter. The construct containing the $445 \mathrm{bp}$ sequence $(-289$ to +156$)$ and GFP or tdTomato was made by PCR amplification of a fragment from mouse genomic DNA using primers $5^{\prime}$ GCATCTTGTTCCTTTGGGCG-3' and 5'-CATTGGAGCAGGTAGTG- $3^{\prime}$ and insertion of this fragment into the UB-GFP or UBtdTomato constructs, replacing the human ubiquitin $\mathrm{C}$ promoter.

The $210 \mathrm{~kb}$ Chx10-containing plasmid $(-109,003$ to $+101,164$ relative to the first nucleotide of GenBank accession number NM_007701) was bacterial artificial chromosome (BAC) RP23-240D15 (BACPAC Resources, Children's Hospital Oakland Research Institute, Oakland, CA). For unbiased CRE screening, an SV40 basal promoter-GFP construct was made by excising the SV40 basal promoter from the GL3 plasmid and inserting it into the UB-GFP construct, replacing the human ubiquitin C promoter. For CRE library construction, $\sim 200 \mathrm{ng}$ of EcoRI-digested BAC DNA was ligated with $\sim 10$ ng of digested SV40 basal promoterGFP vector. An alkaline phosphatase (AP) reporter construct was made by inserting encephalomyocarditis virus internal ribosomel entry site (IRES) (Matsuda and Cepko, 2004) and human placental AP (FieldsBerry et al., 1992) sequences into the SV40 basal promoter-GFP vector downstream of the GFP sequence. Similar to this SV40 basal promoterGFP-IRES-AP vector, an SV40 basal promoter-tdTomato-IRES-AP construct was also made. The constructs containing the $164 \mathrm{bp}$ region $(-17,748$ to $-17,585)$ and the SV40 basal promoter were made by PCR amplification of a fragment from mouse genomic DNA using primers 5'-GAGAAGAGCACTGGCTGGGG-3' and 5' ${ }^{\prime}$-AATTCCATTTGATGCATTAGAACTAATTCTCCTCC- ${ }^{\prime}$ and insertion of this fragment into the SV40 basal promoter-GFP-IRES-AP or SV40 basal promotertdTomato-IRES-AP vector. Grm6, Cabp5, and Chx10 CRE deletion constructs were made using PCR-based mutagenesis to remove sequences detailed in Results.

A CAG-Brn2 construct was made by PCR amplification of a fragment from mouse retinal cDNA using primers 5'-CATGGCGACCGCAGCGTCTAACC- $3^{\prime}$ and $5^{\prime}$-TCACTGGACGGGCGTCTGCAC- ${ }^{\prime}$ and insertion of this fragment into the CAG-GFP vector, replacing the GFP sequence. A CAG-CrxMyc construct was made by PCR amplification of a fragment from mouse retinal cDNA using primers $5^{\prime}$ GTGTGAGGGGACCTATTTCC-3' and 5'-CAAGATCTGAAACTTCCAGG- $3^{\prime}$ and insertion of this fragment and a C-terminal Myc tag sequence (gaacaaaaacttatttctgaagaagatctgtg) into the CAG-GFP vector, replacing the GFP sequence. A CAG-Otx2Myc construct was made by PCR amplification of a fragment from mouse retinal cDNA using primers 5'-CTGGAACGTGGAGGAAGCTG-3' and $5^{\prime}$-CAAAACCTGGAATTTCCATG- $3^{\prime}$ and insertion of this fragment and a C-terminal Myc tag sequence into the CAG-GFP vector, replacing the GFP sequence. CAGCre was from Matsuda and Cepko (2007). The dominant-negative CAGBrn2-DBD-EnR construct was made by PCR amplification of a fragment from mouse retinal cDNA using primers 5'-CCATGGGCACGCCGACCTCAGACGACCTGGAGC- $3^{\prime}$ and 5'-ACCGGTCCGGGAGGGGTCATCCTTTTCTC- ${ }^{\prime}$ and insertion of this fragment and a C-terminal engrailed repressor domain (EnR) (Conlon et al., 1996) into the CAG-GFP vector, replacing the GFP sequence.

Animals. Wild-type (WT) neonates used for electroporation were obtained from pregnant Sprague Dawley rats (Taconic Farms) and CD-1 mice (Charles River Laboratories). Otx $2^{f l o x / f l o x}$ mice were obtained from S. Aizawa (RIKEN Center for Developmental Biology, Kobe, Japan) (Tian et al., 2002). An Otx2 null allele resulted from mating to human $\beta$-actin:Cre transgenic deleter mice (Lewandoski et al., 1997) (The Jackson Laboratory), and mice carrying this mutation were then crossed with $\mathrm{Crx}^{-/-}$mice (Furukawa et al., 1999). Intercrosses of $\mathrm{Otx} 2^{+/-} ; \mathrm{Crx}^{+/-}$ mice led to generation of WT, Otx2 $2^{+-}, \mathrm{Crx}^{-/-}$, and $\mathrm{Otx}^{+/-} ; \mathrm{Crx}^{-/-}$ mice used for RNA in situ hybridization and reverse transcription (RT)PCR. All animals were used in accordance with the guidelines for animal care and experimentation established by the National Institutes of Health and the Harvard Medical Area Standing Committee on Animals.

DNA transfection of retinas by electroporation. DNA transfection by in vivo electroporation was performed as described by Matsuda and Cepko (2004). For cotransfection, equimolar quantities of plasmid were used, and DNA concentration per plasmid was $\sim 2-4 \mathrm{mg} / \mathrm{ml}$. The injection volume was $0.2 \mu \mathrm{l}$. DNA transfection by in vitro electroporation was performed as described by Kim et al. (2008). For unbiased CRE screening, miniprep DNA was used $(\sim 0.1 \mathrm{mg} / \mathrm{ml})$. For all other in vitro electroporations, DNA concentration per plasmid was $\sim 1-2 \mathrm{mg} / \mathrm{ml}$. The volume for in vitro electroporations was $70 \mu \mathrm{l}$.

Histochemical staining. To assess $\beta$-galactosidase activity, 5-bromo-4chloro-3-indolyl- $\beta$-D-galactopyranoside (X-gal) (Research Organics) staining was performed as described by Furukawa et al. (2002), except retinas were fixed in $4 \%$ paraformaldehyde in PBS for $30 \mathrm{~min}$ at $22^{\circ} \mathrm{C}$. 
Retinas were stained for $16 \mathrm{~h}$ at $37^{\circ} \mathrm{C}$. To assess AP activity, staining with 5-bromo-4-chloro-3-indolyl-phosphate (BCIP) (Sigma) and nitroblue tetrazolium (NBT) (Sigma) was performed described by Fields-Berry et al. (1992), except retinas were fixed in $4 \%$ paraformaldehyde in PBS for 5 min on ice. Retinas were stained for $16 \mathrm{~h}$ at $37^{\circ} \mathrm{C}$ and then prepared for sectioning.

Preparation of retinal sections. For experiments in which X-gal or $\mathrm{BCIP/NBT}$ staining was not performed, harvested retinas were dissected or removed from culture and rinsed in $\mathrm{PBS}, \mathrm{pH} 7.4$, fixed in $4 \%$ paraformaldehyde in PBS for $30 \mathrm{~min}$ at $22^{\circ} \mathrm{C}$, and rinsed three times in PBS. All retinas were cryoprotected for $1 \mathrm{~h}$ in $30 \%$ sucrose in PBS and embedded in OCT (Sakura Finetek). Sections $(20 \mu \mathrm{m})$ were cut and slide mounted using a cryostat microtome. Sections were stained overnight with $4^{\prime}, 6$ diamidino-2-phenylindole (DAPI) ( $1 \mu \mathrm{g} / \mathrm{ml}$ in PBS; Roche).

Immunohistochemistry. Retinal sections were stained with antibodies as described by Kim et al. (2008). Primary antibodies included a rabbit anti-Chx10 (1:500) (Morrow et al., 2008), rabbit anti-Pax6 (1:400; Covance), and rabbit anti-cyclin D3 (1:300; Santa Cruz Biotechnology) antibody. A cyanine 3-conjugated goat anti-rabbit IgG secondary antibody was used (1:250; Jackson ImmunoResearch).

Bioinformatic sequence analysis. Sequence analysis was based on the February 2006 ( $\mathrm{mm} 8$ ) mouse genome assembly from the University of California, Santa Cruz (UCSC) Genome Browser Project (Santa Cruz, CA) (Kent et al., 2002). Output of the phastCons program downloaded from the UCSC Genome Browser was used initially to compare syntenic sequences across genomes of different species (Karolchik et al., 2003; Siepel et al., 2005). The rVista program (version 2.0) (Loots and Ovcharenko, 2004) was used to filter isolated CRE sequences through the TRANSFAC database (version 10.2) (Matys et al., 2006) of 467 vertebrate TF binding sequences. Individual mouse sequences were submitted to rVista using the zPicture program, and thresholds for sequence match to TRANSFAC entries were set so that they were optimized for function (Ovcharenko et al., 2004). Percentage identity of mouse CRE sequences to those in other genomes was calculated after alignment using CLUSTALW (Larkin et al., 2007).

Image analysis. Confocal photomicrographs were acquired with a DMRXE upright microscope using a TCS SP2 AOBS laser scanner (Leica). GFP and tdTomato fluorescence intensities of cells were measured from maximum intensity projections ( $16 \mu \mathrm{m}$ thick) of confocal images of retinal sections using NIH ImageJ software (version 1.37a).

Electrophoretic mobility shift assay. Approximately $1 \times 10^{6} 293 \mathrm{~T}$ cells transfected for $36 \mathrm{~h}$ with $3 \mu \mathrm{g}$ of CAG-GFP, CAG-Brn2, CAG-CrxMyc, or CAG-Otx2Myc plasmid DNA using Lipofectamine 2000 (Invitrogen) according to the protocol of the manufacturer were used. Nuclear extracts were prepared from these cells or adult mouse retinas using NEPER nuclear and cytoplasmic extraction reagents (Pierce) according to the protocol of the manufacturer. Complementary oligonucleotides were annealed to make double-stranded probes with tetranucleotide overhangs. These were end labeled with $\left[\alpha{ }^{-32} \mathrm{P}\right] \mathrm{dCTP}$ (GE Healthcare) using Klenow enzyme (Roche). Probes were purified of free nucleotide using Sephadex G-25 spin columns (Roche). Binding reactions were performed for $30 \mathrm{~min}$ at $22^{\circ} \mathrm{C}$ using $1 \mu \mathrm{g}$ of nuclear extract protein and $\sim 2 \times 10^{5} \mathrm{cpm}$ of probe in $10 \%$ glycerol, $10 \mathrm{~mm}$ Tris, $\mathrm{pH} 7.5,50 \mathrm{~mm} \mathrm{KCl}$, $0.5 \mathrm{~mm}$ DTT, and $3 \mu \mathrm{g}$ of poly (dI-dC). Binding reactions were electrophoresed on $6 \%$ polyacrylamide gels (Invitrogen) buffered in $0.5 \times$ Trisborate EDTA at $200 \mathrm{~V}$ for $30 \mathrm{~min}$. Dried gels were exposed to Amersham Hyperfilm MP (GE Healthcare) for $1 \mathrm{~h}$ for transfected cell nuclear extracts or $16 \mathrm{~h}$ for retinal nuclear extracts. These and complementary oligonucleotides with overhangs were used: Grm6 Pax6 site, 5'-ctagCTAAACTTTTAAATCATGAATGAAGTAGA-3'; Grm6 Pou3f2 site, 5' -ctagCTTTAATCTGTTAATGTAGT-3'; Grm6 Crx site, 5' -ctagCAAATCGTTAATCTGCTAAAG-3'; Cabp5 Crx site, 5'-ctagCCTCACCCTAATCCCTCTTTC-3'; Cabp5 5' Brn2 site, 5' -ctagCCCTCTTTCAAAATGTACTATC-3'; Cabp5 Pitx2 site, 5' -ctagAGAGCTCTAATCCCTCCACT-3'; Cabp53' Brn2 site, 5' -ctagTAAGTAGAATTTTCCATGAGCTGT-3'; Chxl0 Crx site, 5'-ctagTTGCCCGCTAATCCCAGCTG-3'; Chx10 Pou3f2 site, 5'-ctagCTGCCATTAAAATATTAAAG-3'; Chx 10 Otx site, $5^{\prime}$-ctagAGATAAATCTAATCGTCTCT3'; and Chx10 Brn2 site, 5'-ctagTCTCTTTATCCAAAATAAGCGACT-3'.

Western blots. Nuclear extract protein $(1 \mu \mathrm{g})$ was subjected to SDS-
PAGE using 4-20\% Tris-glycine gels (Invitrogen) and transferred to nitrocellulose filters (Invitrogen). Membranes were probed with a goat polyclonal anti-Brn2 antibody (1:500, s.c.-6029; Santa Cruz Biotechnology) or a mouse monoclonal anti-Myc antibody (1:500, 9E10, s.c.-40; Santa Cruz Biotechnology) and then with horseradish peroxidaseconjugated donkey anti-goat (1:5000; Jackson ImmunoResearch) or goat anti-mouse (1:5000; Jackson ImmunoResearch) antibodies. Immunoreactivity was revealed using enhanced chemiluminescence detection reagents (GE Healthcare).

RNA in situ hybridization. Hybridization of riboprobes to retinal sections was performed as described by Murtaugh et al. (1999) with modifications detailed by Trimarchi et al. (2007). Riboprobes used have been described previously (Kim et al., 2008).

$R T-P C R$. Total RNA was extracted from postnatal day 14 (P14) mouse retinas using the TRIzol reagent (Invitrogen). Transcriptor reverse transcriptase (Roche) was used to produce cDNA. Real-time PCR was performed using a LightCycler 2000 machine (Roche) with DNA Master SYBR Green I reagents (Roche). Cycle conditions for all genes assayed included an initial denaturation step $\left(95^{\circ} \mathrm{C}\right.$ for $\left.30 \mathrm{~s}\right)$ and then amplification cycles $\left(95^{\circ} \mathrm{C}\right.$ for $0 \mathrm{~s}, 60^{\circ} \mathrm{C}$ for $5 \mathrm{~s}, 72^{\circ} \mathrm{C}$ for $\left.15 \mathrm{~s}\right)$. Primer pairs that spanned at least one intron for each gene were as follows: Grm6 ( $5^{\prime}$ cgtgtacggtgtatgccatc- $3^{\prime}$ and $5^{\prime}$-cagtcagtgtggtcgtttgg- $\left.3^{\prime}\right)$, Cabp5 (5'ggatgattggtgtccaggag $-3^{\prime}$ and $5^{\prime}$-caacagtgccatctccattg- $\left.3^{\prime}\right), C h x 10\left(5^{\prime}\right.$-ttcaatgaagcccactaccc- $3^{\prime}$ and $5^{\prime}$-catactcagccatgacgctg- $\left.3^{\prime}\right), O g 9 x$ ( $5^{\prime}$-cagtcctgtggaggcatctc- $3^{\prime}$ and $5^{\prime}$-atcttggcttcaggcaggtg- $\left.3^{\prime}\right)$, Scgn (5'-cccagaagtggatggatttg- $3^{\prime}$ and $5^{\prime}$-gacacagtgccagctcagac- $\left.3^{\prime}\right)$, and Actb $\left(5^{\prime}\right.$ ctttgcagctccttcgttgc- $3^{\prime}$ and $5^{\prime}$-tcgtcacccacataggagtc- $\left.3^{\prime}\right)$. Relative concentrations were calculated from crossing point analysis and six-log standard curves using LCDA software (version 3.5.28; Roche). Relative concentrations for Grm6, Cabp5, Chx10, Og9x, and Scgn were normalized to those for $A c t b$.

\section{Results \\ Grm6 CRE isolation}

In an initial effort to characterize the CREs regulating bipolar cell genes, an analysis was conducted using in vivo retinal electroporation. A DNA construct containing a $10 \mathrm{~kb}$ mouse genomic fragment ( -9727 to +409 relative to the first nucleotide of GenBank accession number BC021919, NIH) encompassing 5 ' flanking sequence of the Grm6 gene that was inserted upstream of a $L a c Z$ reporter gene was transfected into neonatal rat retinas in vivo. This construct was shown previously to be sufficient to drive LacZ reporter gene expression specifically in ON bipolar cells, in which Grm6 is normally expressed, in transgenic mouse lines (Nakajima et al., 1993; Ueda et al., 1997; Vardi and Morigiwa, 1997). Retinas were also cotransfected with a plasmid containing a broadly active promoter driving GFP expression as a transfection control. Mature retinas were harvested, and histochemical staining revealed reporter gene expression specifically in $\mathrm{ON}$ bipolar cells, as assessed by morphological criteria. Stained cell bodies were present in the upper (scleral) part of the inner nuclear layer (INL) (Fig. 1A), and, in intensely stained cells, it was possible to observe axons that projected to the lower (vitreal) half of the inner plexiform layer (IPL) in which axon terminals were visible, consistent with the morphology of ON bipolar cells. GFP signal from the cotransfected plasmid was observed in many other cell types, including photoreceptor cells in the outer nuclear layer $(\mathrm{ONL})$ and other INL cells (Fig. $1 B$ ), as reported previously (Matsuda and Cepko, 2004).

To determine which sequences within the original $10 \mathrm{~kb}$ genomic fragment were important in driving specific expression, a $5.7 \mathrm{~kb}$ region was removed from the construct (sequence left in construct: -9727 to -8127 and -2331 to +409$)$. Despite expression from the cotransfected GFP plasmid in many ONL and INL cells, LacZ reporter activity was absent from transfected regions, indicating that sequences in the deleted $5.7 \mathrm{~kb}$ region were 

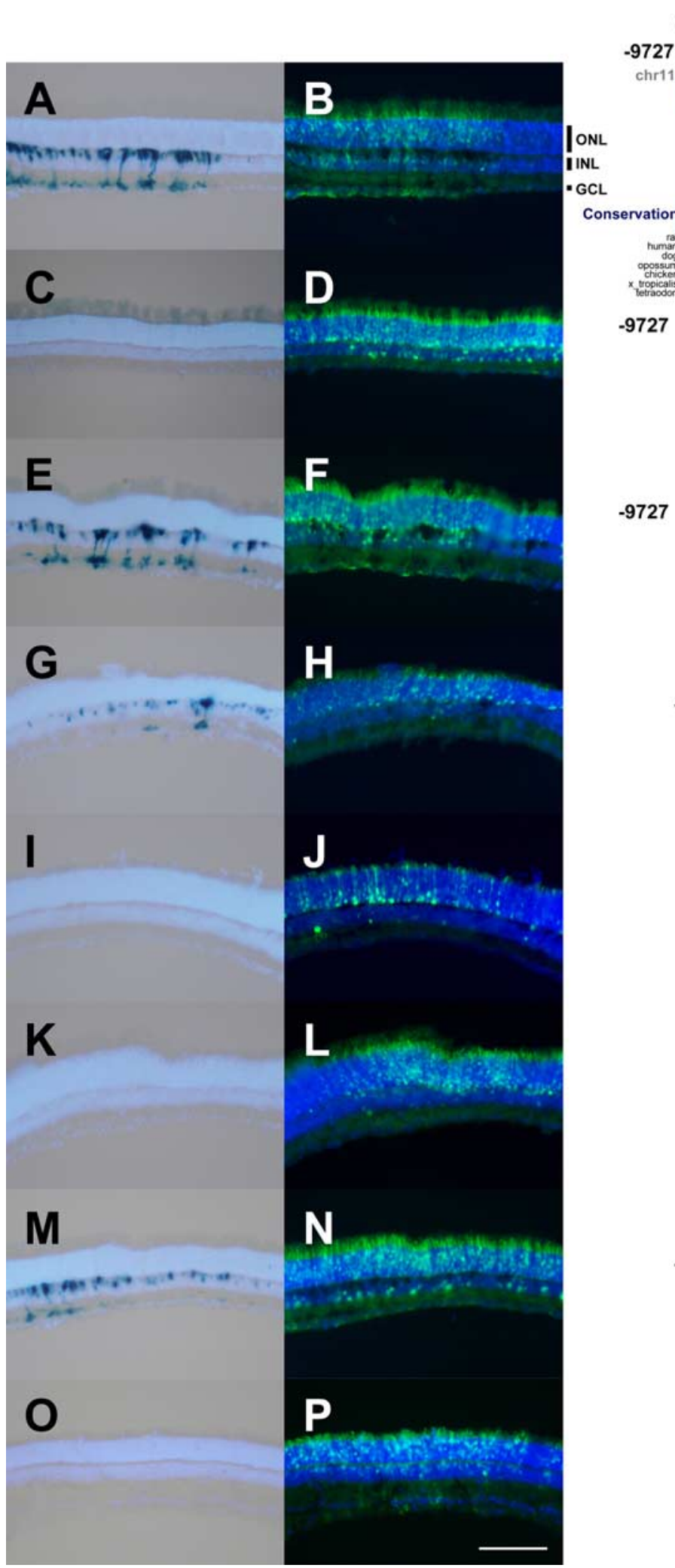

S B M

|ONL
IINL
- GCL
Conse

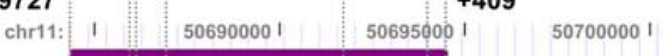

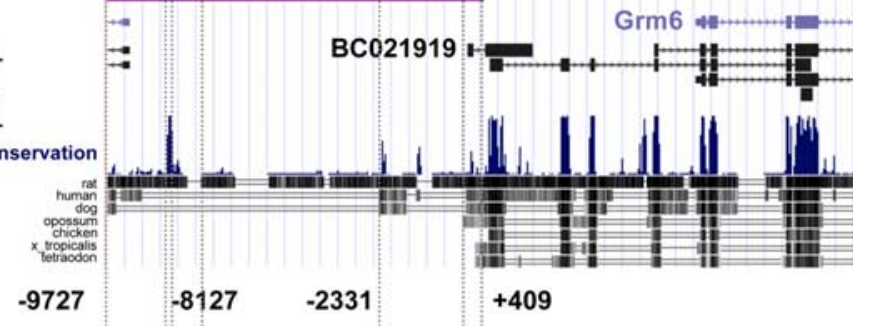

$-972$
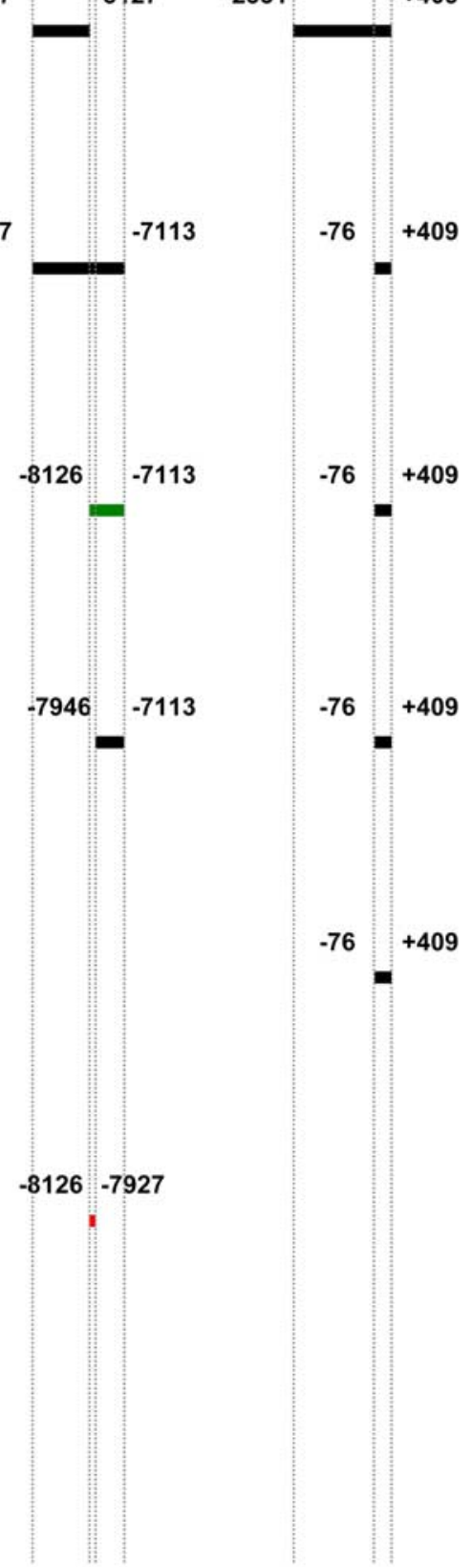

SV40 promoter

.

SV40 promoter

-

Figure 1. Grm6 CRE isolation. Representative sections from in vivo neonatal rat retinal transfections with Grm6-LacZ and UB-GFP or CAG-GFP constructs. Retinas were harvested at P15-P22. $A, C, E, G, I, K, L, M, O, X$-gal (dark blue) and DAPI (light blue) staining. $B, D, F, H, J, L, N, P$, GFP fluorescence (green) and DAPI staining (blue) in the same section. $A$, The $10 \mathrm{~kb} 5$ ' flanking mouse genomic sequence Grm6-LacZ transfection (Ueda et al., 1997). B, UB-GFP cotransfection. C, Bglll deletion construct-LacZ transfection. D, CAG-GFP cotransfection. E, Mscl deletion construct-LacZ transfection. F, CAG-GFP cotransfection. G, The 1 kb critical region-3' 0.5 kb sequence-LacZ transfection. H, CAG-GFP cotransfection. I, The 1 kb critical region without conserved 5' sequence- $3^{\prime}$ 0.5 kb sequence-LacZ transfection. J, CAG-GFP cotransfection. $\boldsymbol{K}$, The 3' 0.5 kb sequence-LacZ transfection. L, CAG-GFP cotransfection. $\boldsymbol{M}$, The 200 bp Grm6-SV40 promoter-LacZ transfection. $\boldsymbol{N}$, UB-GFP cotransfection. 0, SV40 promoter-LacZ transfection. P, UB-GFP cotransfection. Grm6 partial mouse genomic structure is shown in light blue. The $10 \mathrm{~kb} 5{ }^{\prime}$ flanking genomic sequence is shown in purple. Conservation of syntenic regions of genomes of several species is plotted in dark blue. Pairwise comparison of mouse sequence and syntenic regions of other species is plotted below. Numbers in black are sequence positions relative to first nucleotide of accession number BC021919 (GenBank, NIH). The $1 \mathrm{~kb}$ critical region (green). The $200 \mathrm{bp}$ CRE (red). S, Sphl restriction enzyme site; B, Bglll; M, Mscl; N, Nael; GCL, ganglion cell layer. Scale bar, $100 \mu \mathrm{m}$. 


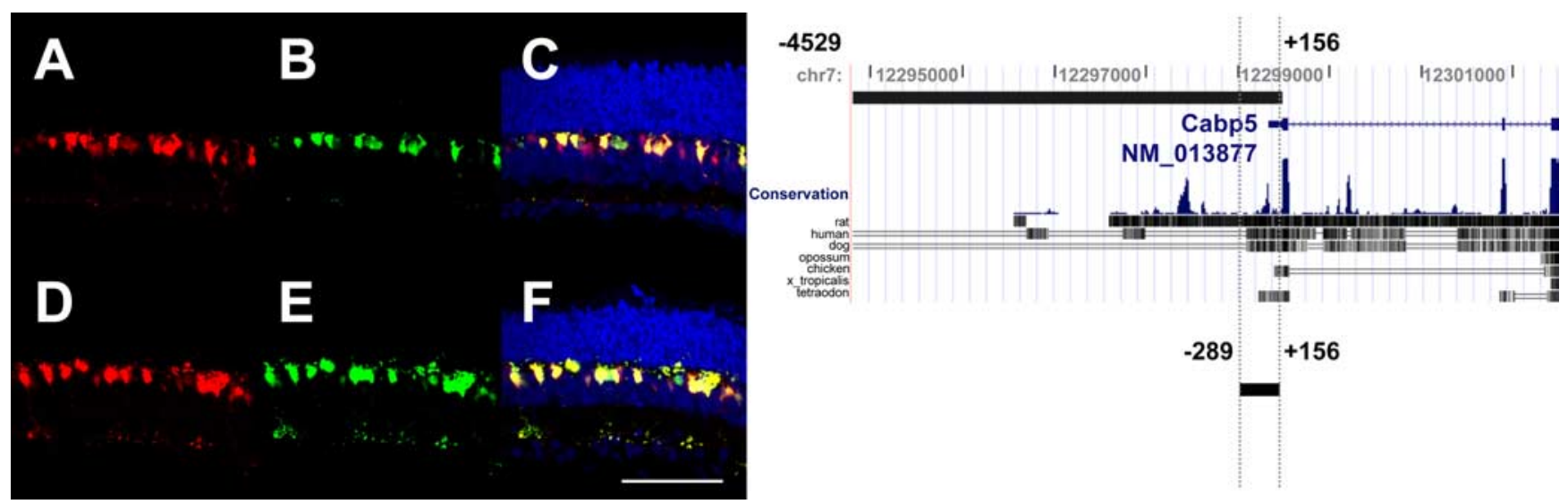

Figure 2. Cabp5 CRE isolation. Representative sections from in vivo neonatal mouse retinal transfections with Cabp5-tdTomato and Cabp5-GFP constructs. Retinas were harvested at P14. A, The $4.7 \mathrm{~kb} 5$ ' flanking mouse genomic sequence-tdTomato transfection (Matsuda and Cepko, 2004). B, The $4.7 \mathrm{~kb} 5$ ' flanking mouse genomic sequence-GFP transfection. C, Merged images, tdTomato fluorescence (red), GFP fluorescence (green), DAPI staining (blue). D, The $4.7 \mathrm{~kb} 5$ ' flanking mouse genomic sequence-tdTomato transfection. $\boldsymbol{E}$, The 445 bp Cabp5-GFP transfection. $\boldsymbol{F}$, Merged images. Cabp5 partial mouse genomic structure is shown in dark blue. The $4.7 \mathrm{~kb} 5$ ' flanking genomic sequence is shown as black rectangle to the left of the Cabp 5 partial mouse genomic structure. Conservation of syntenic regions of genomes of several species is plotted in dark blue. Pairwise comparison of mouse sequence and syntenic regions of other species is plotted below. Numbers in black are sequence positions relative to first nucleotide of GenBank accession numbers NM_013877. Scale bar, $100 \mu \mathrm{m}$.

A
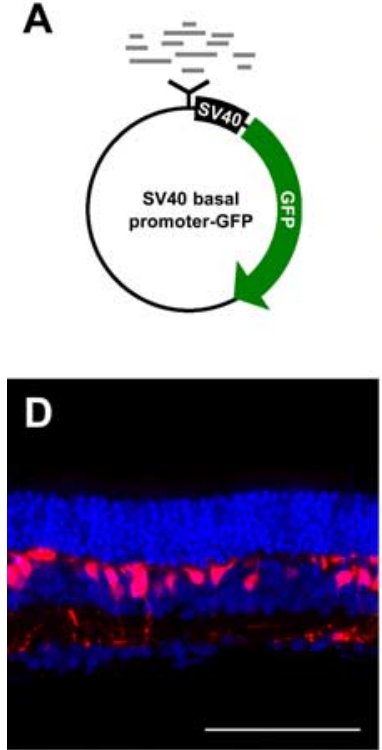

E

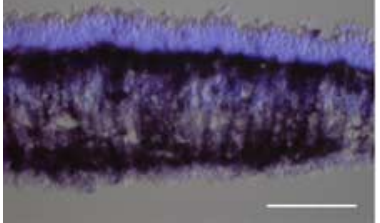

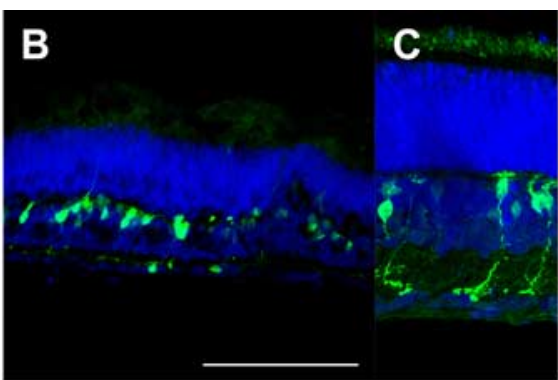
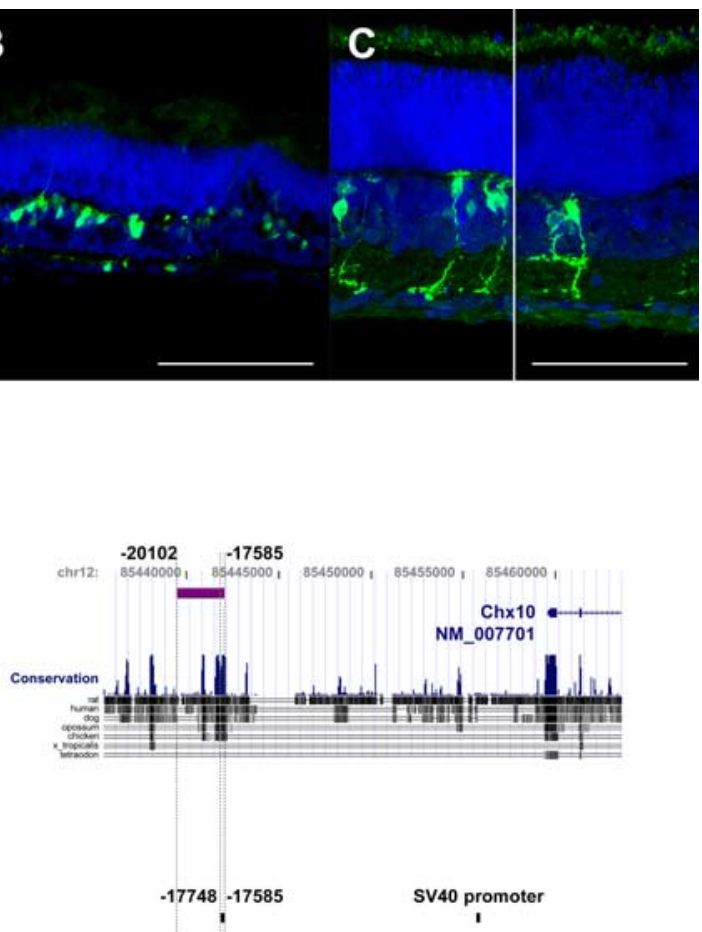

Figure 3. Chx10 CRE screening and isolation. $\boldsymbol{A}$, Unbiased CRE screening scheme. Reporter vector contains a cloning site inserted upstream of an SV40 basal promoter and GFP. A mouse Chx10 BAC was digested with EcoRl, and fragments were used to construct a CRE library. $\boldsymbol{B}$, Representative section from in vitro neonatal mouse transfection of a CRE clone containing five genomic fragments. Retina was harvested after $9 \mathrm{~d}$ of culture. GFP fluorescence (green) and DAPI staining (blue) are shown. $\boldsymbol{C}$, Representative sections from in vivo neonatal rat transfection of positive CRE clone. Retinas were harvested at P14. D, The $2.5 \mathrm{~kb}$ Chx10 SV40 promoter-tdTomato transfection. Retinas were harvested at P14. tdTomato fluorescence (red) is shown. $\boldsymbol{E}$, The $164 \mathrm{bp}$ Chx10-SV40 promoter-GFP-IRES-AP transfection. Retinas were harvested at P14. BCIP/NBT staining (dark purple) is shown. Chx10 partial mouse genomic structure is shown in dark blue. The $2.5 \mathrm{~kb}$ genomic sequence is shown in purple. Conservation of syntenic regions of genomes of several species is plotted in dark blue. Pairwise comparison of mouse sequence and syntenic regions of other species is plotted below. Numbers in black are sequence positions relative to first nucleotide of GenBank accession number NM_007701.Scale bars, $100 \mu \mathrm{m}$. required to drive Grm6 expression (Fig. $1 C)$. A different $7.0 \mathrm{~kb}$ region was deleted from the original $10 \mathrm{~kb}$ genomic sequence (sequence left in construct: -9727 to -7113 and -76 to +409$)$. In retinas transfected with this construct, reporter expression was observed in bipolar cells, indicating that sequence in the deleted region is dispensable for Grm6 expression (Fig. $1 E$ ). Comparison of which sequences overlap in these two deletion constructs suggested that a $1 \mathrm{~kb}$ region $(-8126$ to -7113 ) is critical for expression. Transfection of a construct containing this $1 \mathrm{~kb}$ critical region and a $3^{\prime} 0.5 \mathrm{~kb}$ sequence $(-8126$ to -7113 and -76 to +409$)$ resulted in reporter expression in bipolar cells (Fig. $1 G$ ). The $3^{\prime} 0.5 \mathrm{~kb}$ sequence $(-76$ to +409$)$ alone was insufficient for reporter expression (Fig. $1 \mathrm{~K}$ ), confirming the importance of the $1 \mathrm{~kb}$ critical region in driving Grm6 expression.

To further refine which sequences within this $1 \mathrm{~kb}$ critical region were necessary for expression and based on the hypothesis that important regulatory sequences are conserved across phylogeny, a comparison was made of this mouse sequence and syntenic sequences found in the rat, human, and dog genomes using the PhastCons program (Siepel et al., $2005)$. Within the critical region, only the 5' 200 bp of the critical region $(-8126$ to -7927) exhibited significant conservation (Fig. 1). This mouse sequence was $94 \%$ identical with the syntenic rat sequence (see Fig. $8 A$ ). Similar sequences were also found in syntenic human (78\% identical) and $\operatorname{dog}(72 \%)$ genomic regions but showed lower identity. Removal of almost 


\section{Grm6-SV40 promoter-GFP}

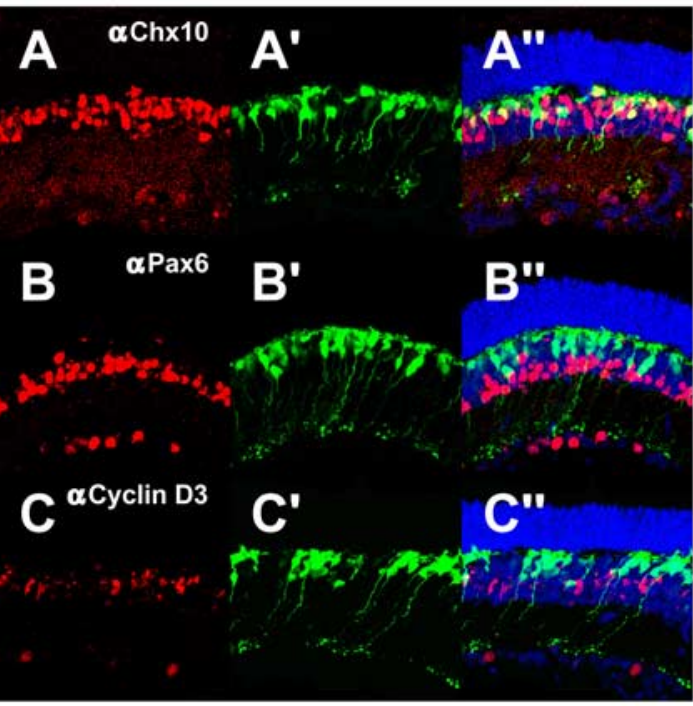

Cabp5-GFP

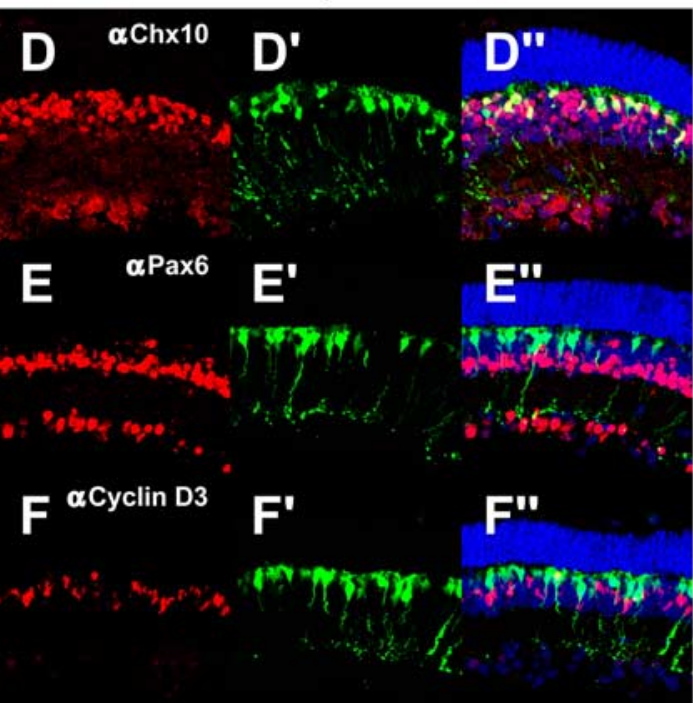

Chx10-SV40 promoter-GFP

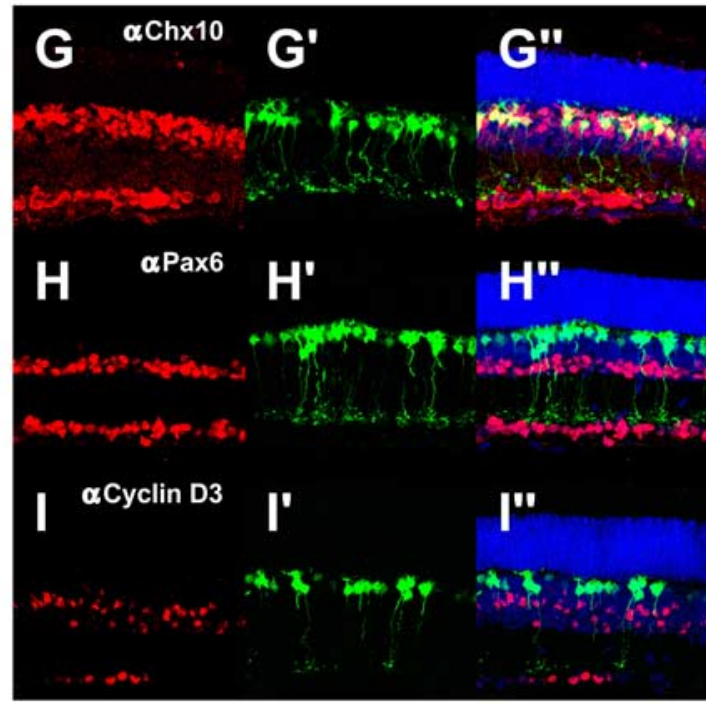

UB-GFP

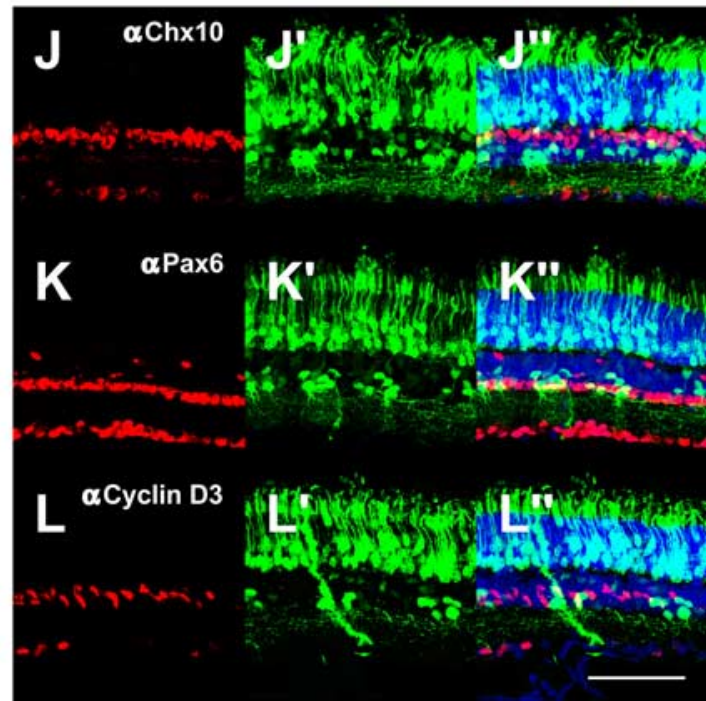

Figure 4. Characterization of Grm6, Cabp5, and Chx10 CREs by labeling of transfected retinas with immunohistochemical markers of bipolar and other retinal cells. Representative sections from in vivo neonatal mouse retinal transfections with the 200 bp Grm6-SV40 promoter-GFP construct $\left(\boldsymbol{A}^{\prime}-\boldsymbol{C}^{\prime}\right)$, 445 bp Cabp5-GFP construct ( $\left.\boldsymbol{D}^{\prime}-\boldsymbol{F}^{\prime}\right)$, 164 bp Chx10-SV40 promoter-GFP construct $\left(G^{\prime}-I^{\prime}\right)$, and UB-GFP $\left(J^{\prime}-L^{\prime}\right)$. Retinas were harvested at P21. $A, D, G, J$, Chx10 antibody staining signal is shown in red. $B, E, H, K$, Pax6 antibody staining signal is shown in red. $C, F, I, L, C y c l i n$ D3 antibody staining signal is shown in red. $A^{\prime \prime}-L^{\prime \prime}$, Merged images, antibody signal (red), GFP fluorescence (green), DAPI staining (blue). Scale bar, $100 \mu \mathrm{m}$.

all of the 5' $200 \mathrm{bp}$ sequence from the construct containing the 1 $\mathrm{kb}$ critical region and $3^{\prime} 0.5 \mathrm{~kb}$ sequence (sequence in left construct: -7946 to -7113 and -76 to +409$)$ resulted in loss of reporter expression (Fig. $1 \mathrm{I}$ ). The 200 bp sequence, positioned 8 $\mathrm{kb}$ upstream of the transcriptional start site $(-8126$ to -7927$)$, together with a heterologous 219 bp SV40 basal promoter was sufficient to drive specific reporter expression in bipolar cells (Fig. $1 M$ ). The SV40 basal promoter alone did not exhibit detectable activity (Fig. 1O). Additional fine-scale analysis of this 200 bp Grm6 CRE is discussed below.

\section{Cabp5 CRE isolation}

A $4.7 \mathrm{~kb}$ mouse genomic fragment $(-4529$ to +156 relative to the first nucleotide of GenBank accession number NM_013877) overlapping the $5^{\prime}$ untranslated region of the Cabp5 gene was inserted upstream of a GFP or tdTomato reporter construct. This genomic fragment was shown previously to direct reporter ex- pression in a subset of bipolar cells (Matsuda and Cepko, 2004).

Consistent with previous results, cotransfection of the $4.7 \mathrm{~kb}$ Cabp5:tdTomato and $4.7 \mathrm{~kb}$ Cabp5:GFP constructs into neonatal mouse retinas in vivo resulted in colabeling of bipolar cells when mature retinas were examined (Fig. 2A-C).

A bioinformatic comparison was made of this mouse Cabp5 flanking sequence and syntenic sequences found in the rat, human, and dog genomes. The 3' $445 \mathrm{bp}$ of the $4.7 \mathrm{~kb}$ sequence exhibited significant conservation across several species. This 445 bp mouse sequence was $90 \%$ identical with the syntenic rat sequence (see Fig. $8 \mathrm{~B}$ ). Similar sequences were also found in syntenic human (64\% identical) and $\operatorname{dog}(64 \%)$ genomic regions but showed lower identity. This 445 bp sequence $(-289$ to +156$)$ was inserted upstream of a GFP reporter construct. Cotransfection of this 445 bp Cabp5-GFP construct and the $4.7 \mathrm{~kb}$ Cabp5:tdTomato construct resulted in colabeling of bipolar cells, indicating 


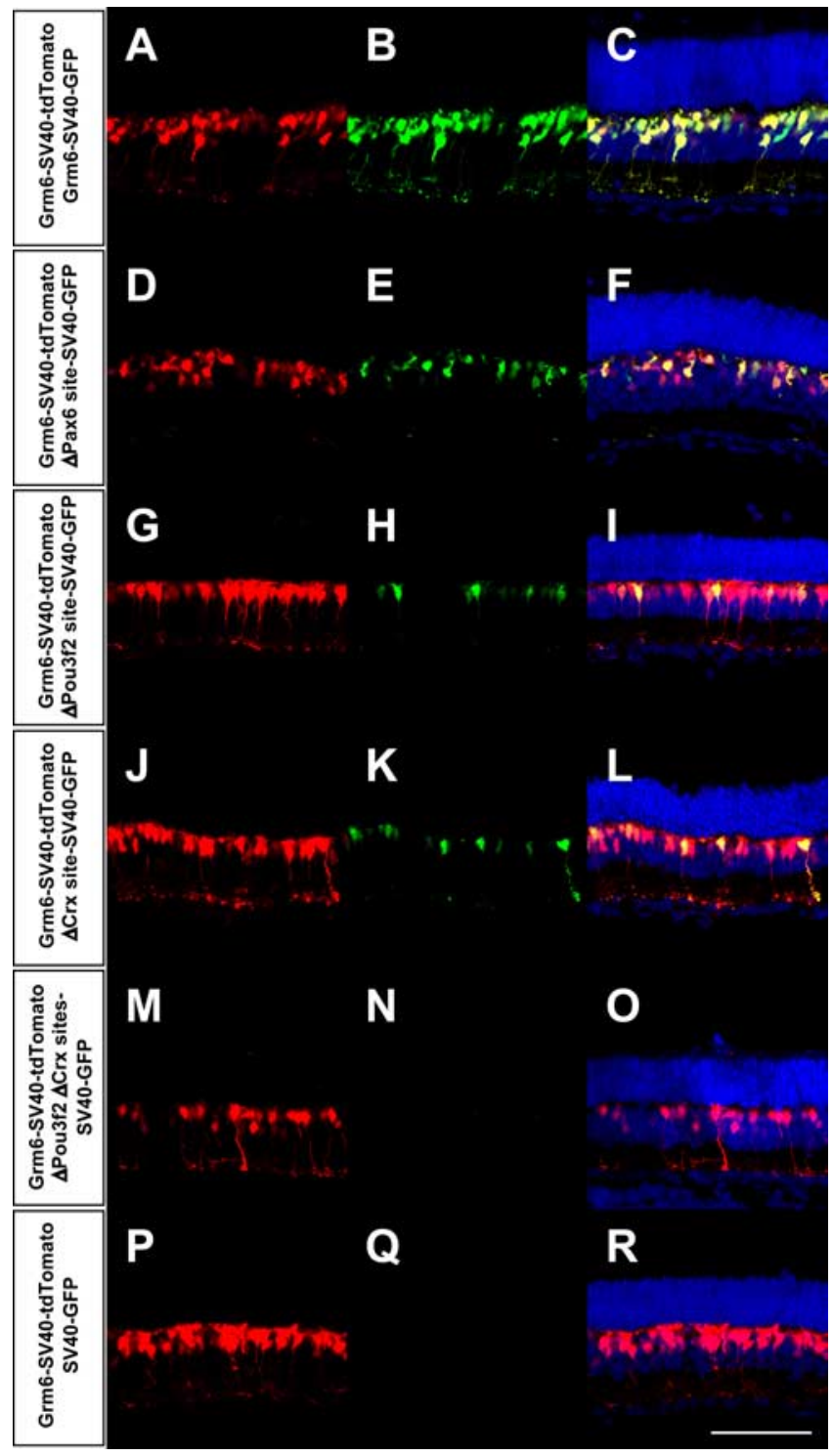

Figure 5. Grm6 CRE deletion analysis. Representative sections from in vivo neonatal mouse retinal transfections with the $200 \mathrm{bp} \mathrm{Grm6-SV40} \mathrm{promoter-tdTomato} \mathrm{construct} \mathrm{and} \mathrm{Grm6-}$ SV40 promoter-GFP deletion constructs. Retinas were harvested at P14-P21. A, D, G, J, M, $\boldsymbol{P}$, The 200 bp Grm6-SV40 promoter-tdTomato transfection. $\boldsymbol{C}, \boldsymbol{F}, \boldsymbol{I}, \boldsymbol{L}, \mathbf{O}, \boldsymbol{R}$, Merged images, tdTomato fluorescence (red), GFP fluorescence (green), DAPI staining (blue). $\boldsymbol{B}$, The $200 \mathrm{bp}$ Grm6-SV40 promoter-GFP transfection. $\boldsymbol{E}$, Pax6 site deletion. $\boldsymbol{H}$, Pou3f2 site deletion. $\boldsymbol{K}, \mathbf{C r}$ site deletion. $\boldsymbol{N}$, Pou3f2 and Crx site deletion. Q, SV40 promoter-GFP transfection. Scale bar, $100 \mu \mathrm{m}$.

that these 445 bp are sufficient to promote Cabp5 expression (Fig.

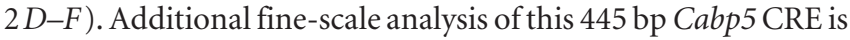
discussed below.

\section{Chx10 CRE isolation}

A previous study characterized a $2.4-\mathrm{kb}$ Chx10 CRE overlapping the $5^{\prime}$ untranslated region that was sufficient to drive reporter expression in dividing progenitor cells and bipolar cells in transgenic mouse lines (Rowan and Cepko, 2005). In an effort to identify additional $C h \times 10$ regulatory elements, an unbiased screen for CREs was conducted. A $210 \mathrm{~kb}$ BAC containing the Chx10 gene ( $-109,003$ to $+101,164$ relative to the first nucleotide of GenBank accession number NM_007701) was digested with a restriction enzyme, and fragments were cloned into a reporter vector

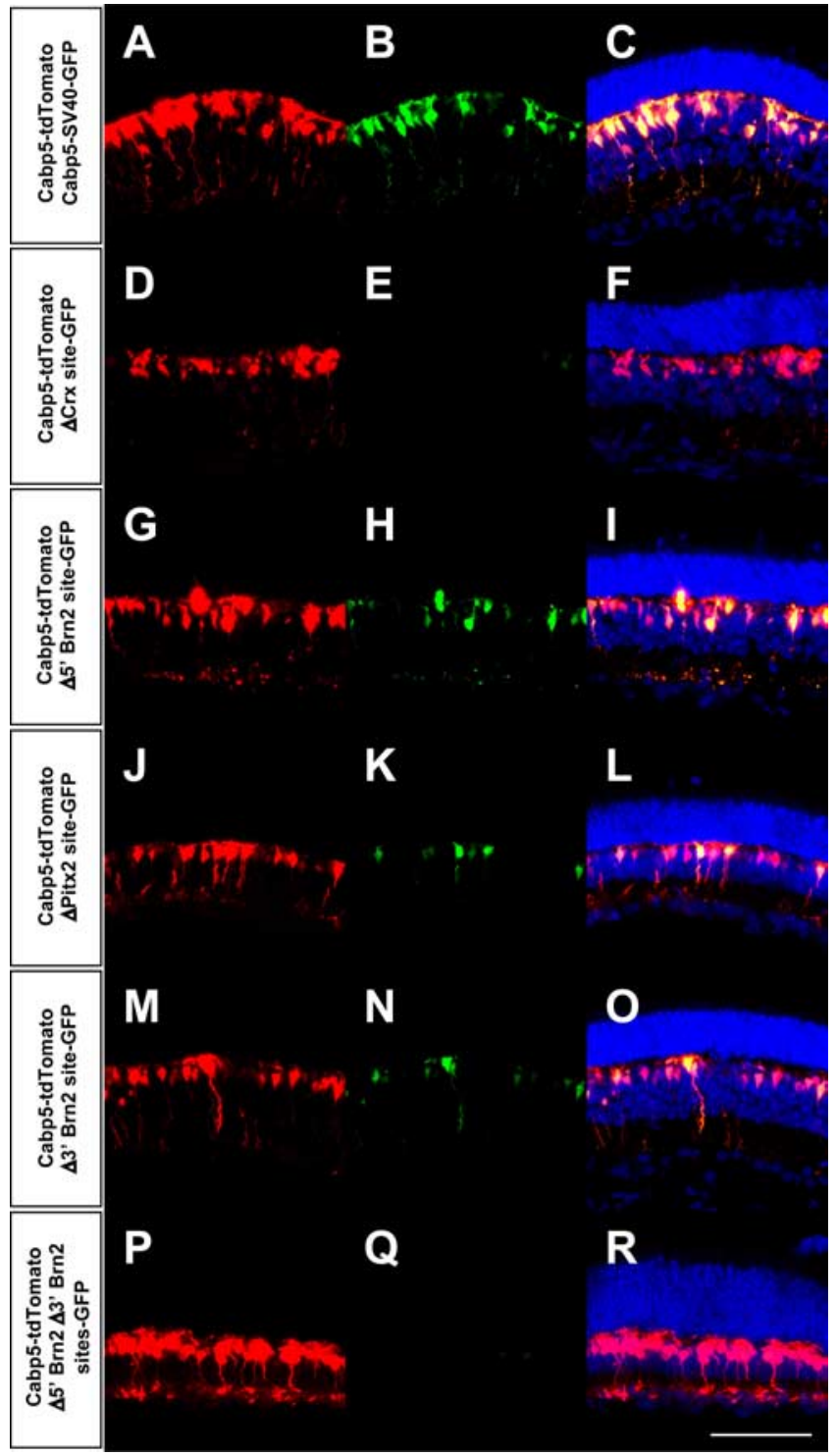

Figure 6. Cabp5 CRE deletion analysis. Representative sections from in vivo neonatal mouse retinal transfections with the 445 bp Cabp5-tdTomato construct and Cabp5-GFP deletion constructs. Retinas were harvested at P14. $\boldsymbol{A}, \boldsymbol{D}, \mathbf{G}, \boldsymbol{J}, \boldsymbol{M}, \boldsymbol{P}$, The 445 bp Cabp5-tdTomato transfection. $\boldsymbol{C}, \boldsymbol{F}, \boldsymbol{I}, \boldsymbol{L}, \mathbf{O}, \boldsymbol{R}$, Merged images, tdTomato fluorescence (red), GFP fluorescence (green), DAPI staining (blue). B, The 445 bp Cabp5-GFP transfection. $\boldsymbol{E}$, Crx site deletion. $\boldsymbol{H}$, The $5^{\prime}$ Brn2 site deletion. $\boldsymbol{K}$, Pitx2 site deletion. $\boldsymbol{N}$, The 3' Brn2 site deletion. $\boldsymbol{Q}$, The 5' Brn2 and 3' Brn2 site deletion. Scale bar, $100 \mu \mathrm{m}$.

upstream of an SV40 basal promoter and a GFP reporter (Fig. $3 A$ ). Cloned fragments were tested for CRE activity by transfection by in vitro electroporation into neonatal mouse retinal explants. After $9 \mathrm{~d}$ of culture, retinas were examined for GFP expression. One of the 20 constructs tested was able to drive GFP expression in bipolar cells (Fig. 3B). Transfection of this construct into rat retinas by in vivo electroporation also resulted in specific reporter expression in bipolar cells, including bipolar cells projecting to the upper and lower half of the IPL, consistent with the pan-bipolar cell expression of Chx10 (Fig. 3C) (Liu et al., 1994; Burmeister et al., 1996; Rowan and Cepko, 2004).

Sequencing of the insert revealed the presence of five distinct genomic fragments ( -2933 to $-125 ;-99,065$ to $-95,466$; $-20,102$ to $-17,589$; $+41,068$ to $+41,175$; and $-33,406$ to $-33,367)$, all oriented in the forward direction relative to the 


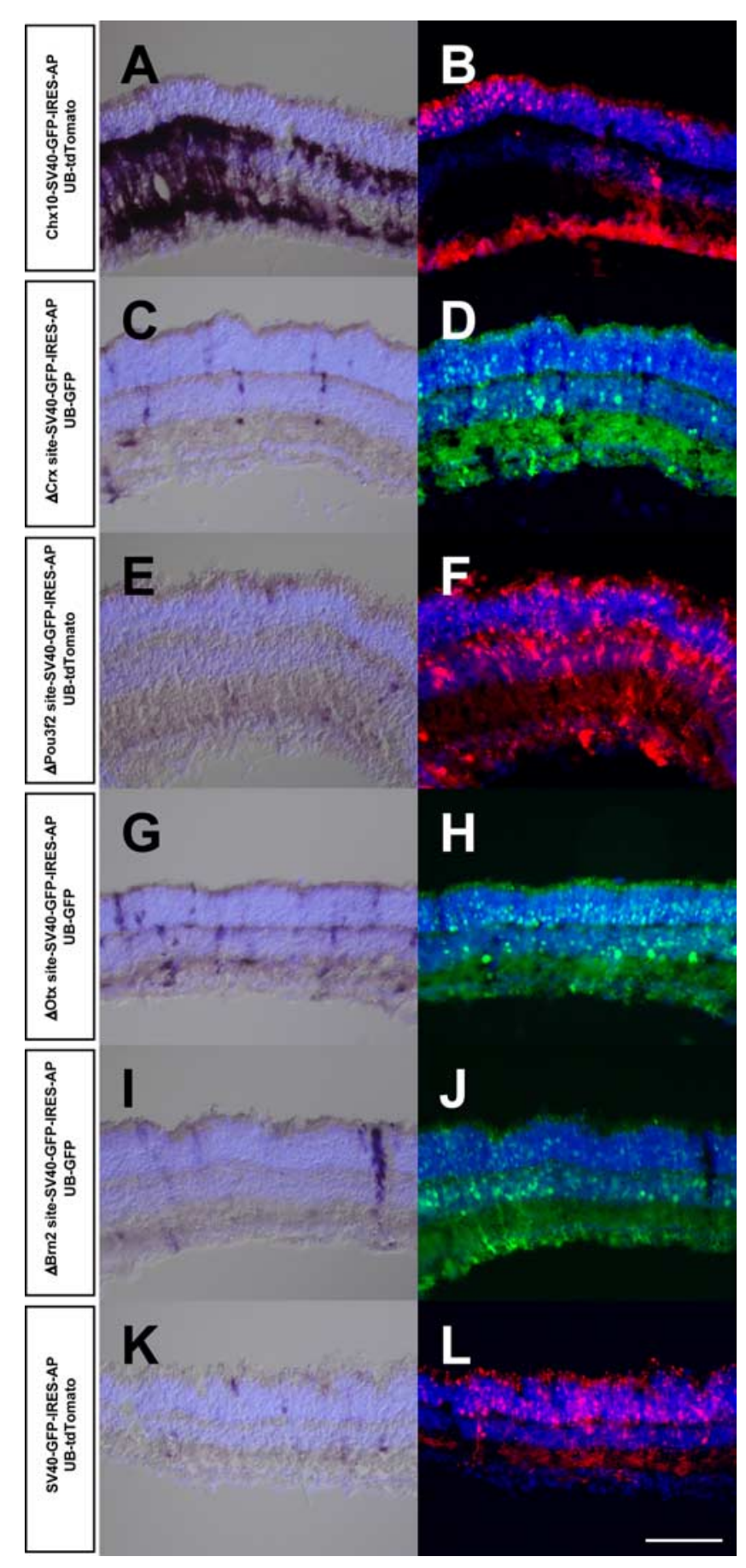

Figure 7. Chx10 CRE deletion analysis. Representative sections from in vivo neonatal mouse retinal transfections with the $164 \mathrm{bp}$ Chx10-SV40 promoter-GFP-IRES-AP construct, Chx10SV40 promoter-GFP deletion constructs, and UB-tdTomato or UB-GFP constructs. Retinas were harvested at P14-P21. $\boldsymbol{A}, \boldsymbol{C}, \boldsymbol{E}, \mathbf{G}, \boldsymbol{I}, \boldsymbol{K}, \mathrm{BCIP} / \mathrm{NBT}$ (dark purple) and DAPI (light blue) staining. $\boldsymbol{B}, \boldsymbol{D}, \boldsymbol{F}, \boldsymbol{H}, \boldsymbol{J}, \boldsymbol{L}$, tdTomato fluorescence (red), GFP fluorescence (green), DAPI staining (blue). $\boldsymbol{A}$, The 164 bp Chx10-SV40 promoter-GFP-IRES-AP transfection. C, Crx site deletion. $\boldsymbol{E}$, Pou3f2 site deletion. $\mathbf{G}, \mathbf{0 t x}$ site deletion. I, Brn2 site deletion. $\boldsymbol{K}$, SV40 promoter-GFP-IRES-AP transfection. Scale bar, $100 \mu \mathrm{m}$.

direction of Chx10 transcription. The middle $2.5 \mathrm{~kb}$ fragment $(-20,102$ to $-17,585)$ situated $19 \mathrm{~kb}$ upstream of the Chx10 transcriptional start site together with an SV40 basal promoter was sufficient to drive expression of a fluorescent reporter construct specifically in bipolar cells when transfected into mouse retinas by in vivo electroporation (Fig. $3 D$ ). The SV40 basal pro- moter alone exhibited virtually no detectable background expression (see Fig. 5Q).

A comparison was made of this $2.5 \mathrm{~kb}$ Chx10 CRE sequence and syntenic sequences found in other vertebrate genomes. The 3' $164 \mathrm{bp}$ of the $2.5 \mathrm{~kb}$ sequence exhibited significant conservation across several species (rat, 95\% identical; human, 91\%; dog, 92\%; opossum, 88\%; chicken, 85\%) (see Fig. 8C). This 164 bp sequence $(-17,748$ to $-17,585)$ together with an SV40 basal promoter was sufficient to drive specific AP reporter expression in bipolar cells (Fig. 3E). Additional fine-scale analysis of this $164 \mathrm{bp}$ Chx10 CRE is discussed below. Because Chx10 is normally expressed in both bipolar cells and dividing progenitor cells, the 164 bp CRE was tested for activity in embryonic retinas when many progenitor cells are present and bipolar cells are not yet present. Reporter expression was not observed after in vitro transfection of plasmids with the164 bp sequence $(-17,748$ to $-17,585)$ together with an SV40 basal promoter inserted upstream of a tdTomato construct, suggesting a specific role for this CRE in Chx10 bipolar cell expression (supplemental Fig. 1, available at www.jneurosci.org as supplemental material) (SV40 promoter-tdTomato fluorescence to UB-GFP fluorescence ratio, $0.25 \pm 0.05$; 164 bp Chx10-SV40 promoter-tdTomato fluorescence to UBGFP fluorescence ratio, $0.23 \pm 0.02$; mean \pm SEM; $n=3$ retinas per construct). The AP reporter was not used in the in vitro transfections of embryonic retinas because of high background activity of the SV40 basal promoter, which contrasts with results from in vivo transfections of neonatal retinas (see Fig. $7 K$ ).

The identity of cells expressing the 200 bp Grm6-SV40 promoter-GFP, 445 bp Cabp5-GFP, and 164 bp Chx10-SV40 promoter-GFP constructs was ascertained using immunohistochemical analysis (Fig. 4). Virtually all GFP-positive cells expressed Chx10, which marks all bipolar cells and a subset of Müller glial cells (Fig. $4 A^{\prime \prime}, D^{\prime \prime}, G^{\prime \prime}$ ) (Liu et al., 1994; Burmeister et al., 1996; Rowan and Cepko, 2004). In rare cases in which a reporter-positive cell body appeared unlabeled by the Chx10 antiserum in a maximum intensity projection of confocal images, examination of individual optical sections revealed absence of most or all of a DAPI-stained nucleus, in which Chx10 immunoreactivity would normally be confined. Almost no reporterexpressing cells were labeled with a Pax6 antibody, which marks amacrine, horizontal, and ganglion cells (Fig. $4 B^{\prime}, E^{\prime}, H^{\prime}$ ) (de Melo et al., 2003). Similarly, virtually no reporter-expressing cells were labeled with a cyclin D3 antibody, which marks Müller glial cells (Fig. 4C $, F^{\prime}, I^{\prime}$ ) (Dyer and Cepko, 2000). Reporterexpressing cells were almost never found in the outer nuclear layer, in which rod and cone photoreceptor cells are located. It should be noted that transfection of DNA constructs by electroporation with a broadly active promoter driving GFP into neonatal rodent retinas does not lead to reporter expression in horizontal cells, and thus reporter activity in this cell type was not examined (Matsuda and Cepko, 2004). Together, the data indicate that the great majority of cells expressing the 200 bp Grm6SV40 promoter-GFP, 445 bp Cabp5-GFP, and 164 bp Chx10 SV40 promoter-GFP constructs are bipolar cells. As a positive control, immunohistochemistry was also performed with retinas transfected with UB-GFP (Fig. $4 J^{\prime}-L^{\prime}$ ).

\section{CRE deletion analysis}

In an additional effort to characterize the transcriptional programs regulating bipolar cell genes, the 200 bp Grm6 CRE, 445 bp Cabp5 CRE, and 164 bp Chx10 CRE sequences were subjected to bioinformatic analysis to identify putative transcription factor binding sites (TFBSs) conserved in genomes of several species. 
This was done using the rVista program (version 2.0) (Loots and Ovcharenko, 2004) to filter sequences through the TRANSFAC database (version 10.2) (Matys et al., 2006) of 467 vertebrate TF binding sequences. Each of the three regulatory elements had putative binding sites for paired-type and POU homeodomaincontaining TFs. The 200 bp Grm6 CRE contained conserved sequences matching the Pax6, Pou3f2, and Crx TFBS matrices annotated in the TRANSFAC database (see Fig. $8 A$ ). In contrast, the $445 \mathrm{bp}$ Cabp5 CRE contained marginally conserved sequences matching the Crx, Brn2, and Pitx2 TFBS matrices (see Fig. 8 B). Finally, the $164 \mathrm{bp}$ Chx10 CRE contained highly conserved sequences matching the Crx, Pou3f2, Otx, and Brn2 TFBS matrices (see Fig. 8C).

The occurrence of putative paired-type and POU homeodomain-containing TF$\mathrm{BSs}$ in each of the regulatory sequences suggested that these elements might be important for expression of these bipolar cell genes. To address this possibility, deletions of each of these sites were made individually and in various combinations, and reporter constructs were transfected into mouse retinas in vivo. In a positive control experiment, cotransfection of equimolar amounts of plasmids containing the 200 bp Grm6 CRE and an SV40 basal promoter inserted upstream of either a tdTomato construct or a GFP construct resulted in a high incidence of colabeling of bipolar cells (Fig. 5A-C). This tdTomatocontaining plasmid was then cotransfected as a control together with deletion constructs inserted upstream of an SV40 basal promoter and GFP. Fluorescent reporters were used to facilitate assessment of coexpression. Constructs containing the 200 bp CRE with the putative Pax6 site (acttttaaatcatgaatgaagtag) deleted were still able to drive GFP reporter expression in bipolar cells (Fig. 5D-F). Deletion of the putative Pou3f2 site (ctgttaatgt) resulted in a decrease of GFP fluorescence in bipolar cells with only the most strongly transfected cells exhibiting GFP expression (Fig. 5G-I). Deletion of the putative Crx site (cgttaatctgcta) also resulted in a diminution of GFP signal from bipolar cells (Fig. 5J-L). Deletion of both the putative Pou3f2 and Crx sites led to an even greater reduction of GFP fluorescence in bipolar cells (Fig. 5M-O). The putative Pou3f 2 and Crx sites are thus important in activating Grm6 reporter expression. The SV40 basal promoter alone exhibited virtually no detectable background GFP expression (Fig. $5 Q$ ). These results were quantitated by measuring the ratio of GFP fluorescence to tdTomato fluorescence in bipolar cells (see Fig. 8D). hoc test).
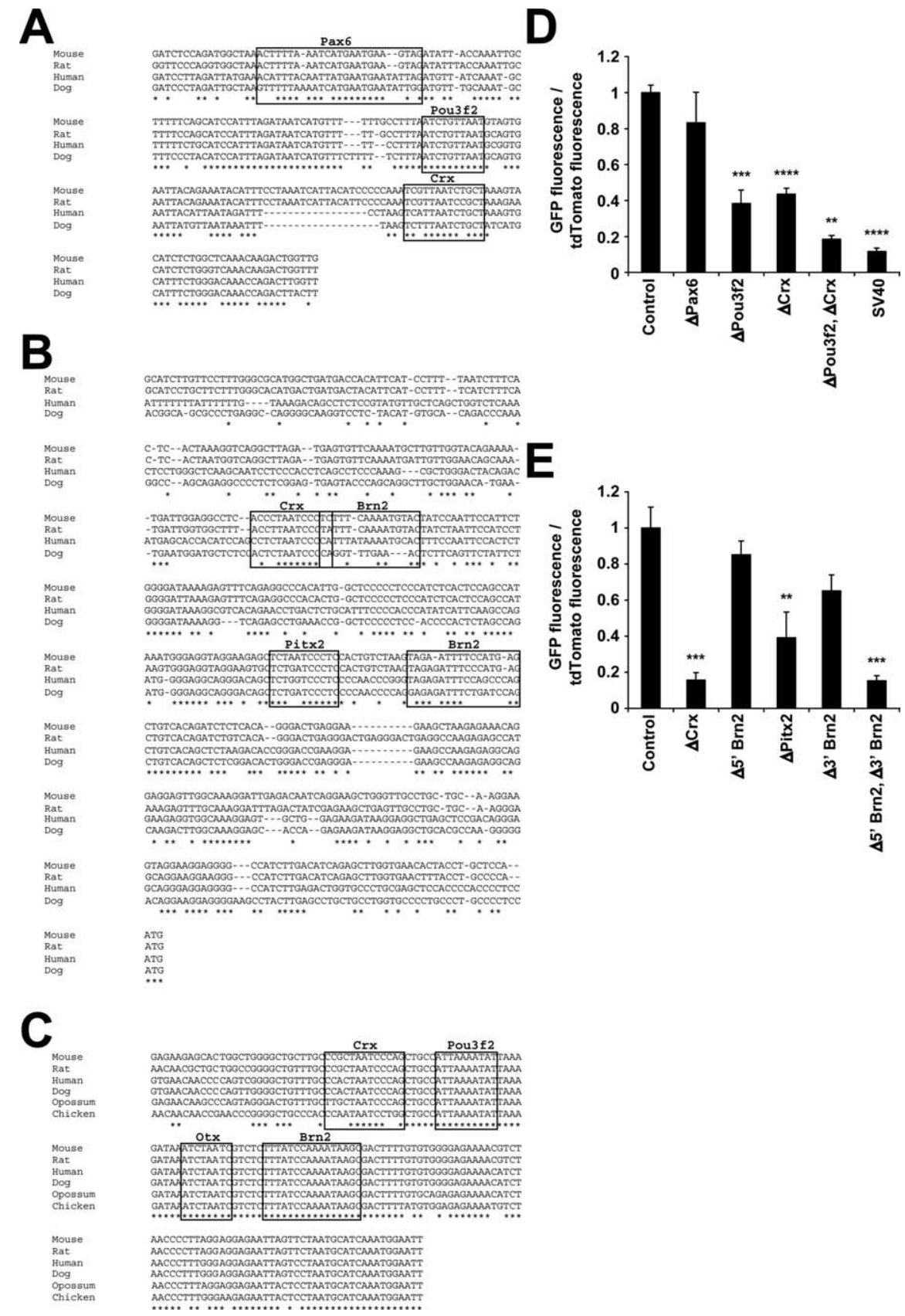

Figure 8. Conservation of putative transcription factor binding sites in Grm6, Cabp5, and Chx10 CREs and quantitation of CRE deletion analyses. A, Alignment of mouse 200 bp Grm6 CRE and syntenic sequence from rat, human, and dog genomes. Asterisks denote conserved nucleotides. Pax site, Pou3f2 site, and Crx site are boxed. B, Alignment of mouse 445 bp Cabp5 CRE and syntenic sequence from rat, human, and dog genomes. Crx site, 5' Brn2 site, Pitx2 site, and 3' Brn2 site are boxed. C, Alignment of mouse $164 \mathrm{bp}$ Chx 10 CRE and syntenic sequence from rat, human, dog, opossum, and chicken genomes. Crx site, Pou3f2 site, $0 \mathrm{tx}$ site, and Brn2 site are boxed. D, GFP fluorescence to tdTomato fluorescence ratios are shown for the $200 \mathrm{bp}$ Grm6-SV40 promotertdTomato and Grm6-SV40 promoter-GFP control and deletion constructs. E, GFP fluorescence to tdTomato fluorescence ratios are shown for the $445 \mathrm{bp} \mathrm{Cabp5-tdTomato} \mathrm{and} \mathrm{Cabp5-GFP} \mathrm{control} \mathrm{and} \mathrm{deletion} \mathrm{constructs.} \mathrm{Mean} \pm$ SEM is shown ( $n=3$ retinas per construct). Comparison with control: ${ }^{* *} p<0.01,{ }^{* * *} p<0.001,{ }^{* * * *} p<0.0001$ (1-way ANOVA and 1-tailed Tukey's post

The putative Crx, Brn2, and Pitx2 sites identified in the Cabp5 CRE were tested in a similar manner. The 445 bp Cabp5 CRE inserted upstream of a tdTomato construct was used as a positive control, and deletion constructs were inserted upstream of GFP. Deletion of the putative Crx site (ccctaatccctct) resulted in a marked reduction of GFP signal from bipolar cells (Fig. 6D-F). Deletion of the $5^{\prime}$ putative Brn2 site (tctttcaaaatgtact) (Fig. $6 G-$ 


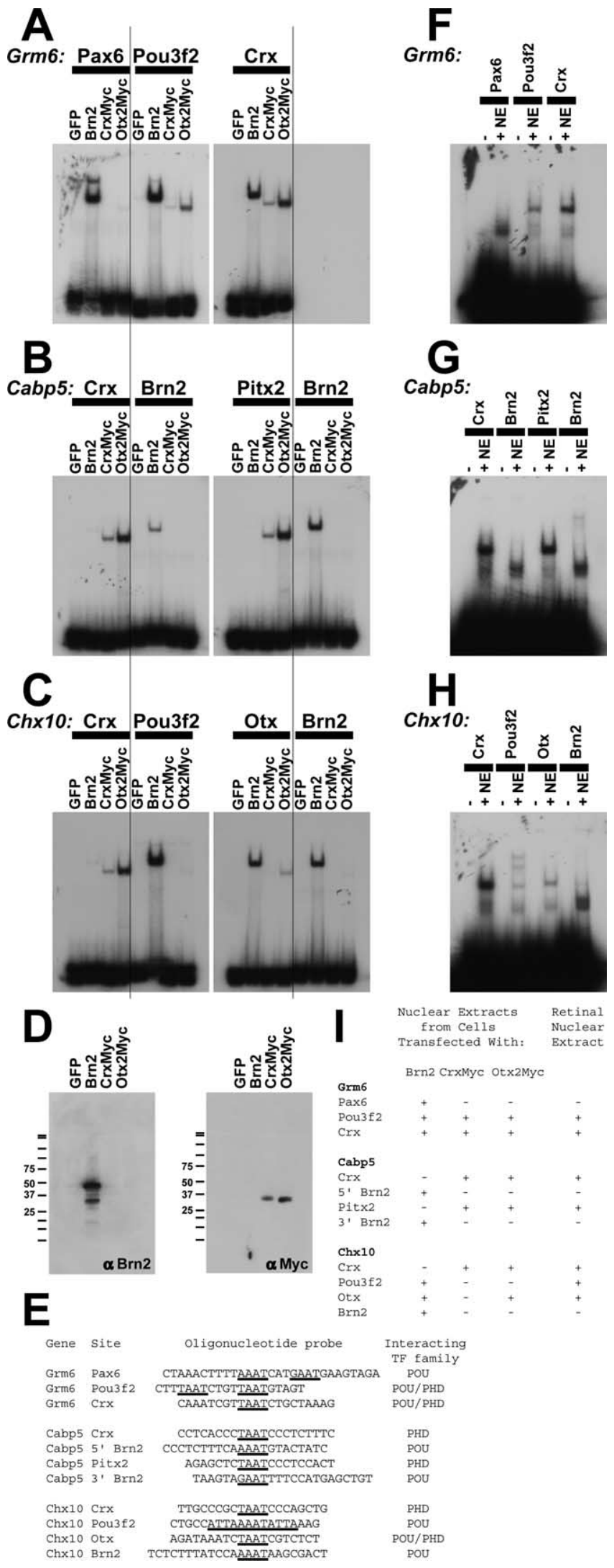

Figure 9. EMSA analysis. Autoradiograms of EMSAs using nuclear extract from 293T cells transfected with CAG-GFP, CAG-Brn2, CAG-CrxMyc, or CAG-0tx2Myc ( $\boldsymbol{A}-\mathbf{C})$ and nuclear extract from adult mouse retinas $(\boldsymbol{F}-\boldsymbol{H}) . \boldsymbol{A}, \boldsymbol{F}$, EMSA results using oligonucleotide probes overlapping the Grm6 Pax6, Pou3f2, and Crx sites. Negative control reactions without nuclear extract $(-)$. Experimental reactions with nuclear extract ( $+\mathrm{NE}) . B, G$, EMSA results using oligonucleotide probes overlapping the Cabp5 $\mathrm{Crx}, 5^{\prime}$ Brn2, Pitx2, and 3' Brn2 sites. C, H, EMSA results
I), the putative Pitx2 site (ctctaatcctcc) (Fig. $6 J-L$ ), or the $3^{\prime}$ putative Brn2 site (agaattttccatgagc) (Fig. 6M-O) led to a slight diminution of GFP fluorescence in bipolar cells. Deletion of both the $5^{\prime}$ putative Brn2 site and $3^{\prime}$ putative Brn2 site resulted in a near total loss of GFP signal from bipolar cells (Fig. $6 P-R$ ). The putative Crx site alone and the putative Brn2 sites together are thus critical for driving Cabp5 reporter expression. Quantitation of these results is shown in Figure $8 E$.

To test the importance of putative TFBSs in the $164 \mathrm{bp}$ Chx10 CRE, deletion constructs were cotransfected with a plasmid containing a broadly active promoter driving GFP or tdTomato as a transfection control. Deletion of the putative Crx site (ccgctaatcccag) resulted in reduction of AP reporter-positive bipolar cells (Fig. 7C). Some rod photoreceptor and cone OFF bipolar cells projecting to the upper half of the IPL were visible, suggesting that this site is weakly repressive in rod photoreceptor cells and is not absolutely required for expression in cone OFF bipolar cells. Deletion of the putative Pou3f2 site (ttaaaatatt) led to near complete loss of reporter-positive cells (Fig. 7E). Deletion of the putative Otx site (ctaatcgt) resulted in reduction of reporterpositive bipolar cells (Fig. 7G). Some rod photoreceptor and cone OFF bipolar cells projecting to the upper half of the IPL were observed, suggesting that this site is weakly repressive in rod photoreceptor cells and is not absolutely required for expression in cone OFF bipolar cells. Deletion of the putative Brn2 site (ttatccaaaataagcg) led to reduction of reporter-positive cells (Fig. 7I). Some Müller glial cells were visible, suggesting that this site is weakly repressive in Müller glial cells. The putative Crx, Pou3f2, Otx, and Brn2 sites are thus each important in activating Chx10 expression in bipolar cells (Fig. 8).

\section{Characterization of protein interactions with putative binding sites}

To investigate whether POU and paired-type homeodomaincontaining TFs can interact in vitro with putative binding site sequences, electrophoretic mobility shift assays (EMSAs) were conducted using nuclear extracts from transfected 293T cells and from adult mouse retinas. Nuclear extracts from cells transfected with Brn2, Crx, and Otx2 were used for binding experiments because these POU and paired-type homeodomain-containing TFs have been shown to be expressed in developing and mature bipolar cells, among other retinal cell types (Chen et al., 1997; Furukawa et al., 1997; Rowan and Cepko, 2005; Koike et al., 2007). Binding activity in nuclear extracts from cells transfected with a Brn2 expression construct interacted with double-stranded oligonucleotides overlapping the putative Pax6 site in the Grm6 CRE (Fig. $9 A)$. Binding activity was not observed when nuclear extracts from cells transfected with a GFP, myc-tagged Crx (CrxMyc), or myc-tagged Otx2 (Otx2Myc) expression construct was used, suggesting that Brn2 can interact with this Pax6 site with some degree of selectivity. Nuclear extracts from cells transfected with Brn2, CrxMyc, and Otx2Myc each contained binding activity that could interact with oligonucleotides contain-

using oligonucleotide probes overlapping the Chx10 Crx, Pou3f2, Otx, and Brn2 sites. D, Western blot analysis of nuclear extracts using an anti-Brn2 or anti-Myc antibody. Numbers denote molecular weight in kilodaltons. $\boldsymbol{E}$, Sequence alignment of oligonucleotides overlapping the Grm6, Cabp5, and Chx10 sites. Underlined sequences are TAAT sequences or closest matches. Summary of interactions with TFs from two families is listed on right. POU, POU homeodomaincontaining TF interaction; PHD, paired-type homeodomain-containing TF interaction. I, Summary of interactions. 


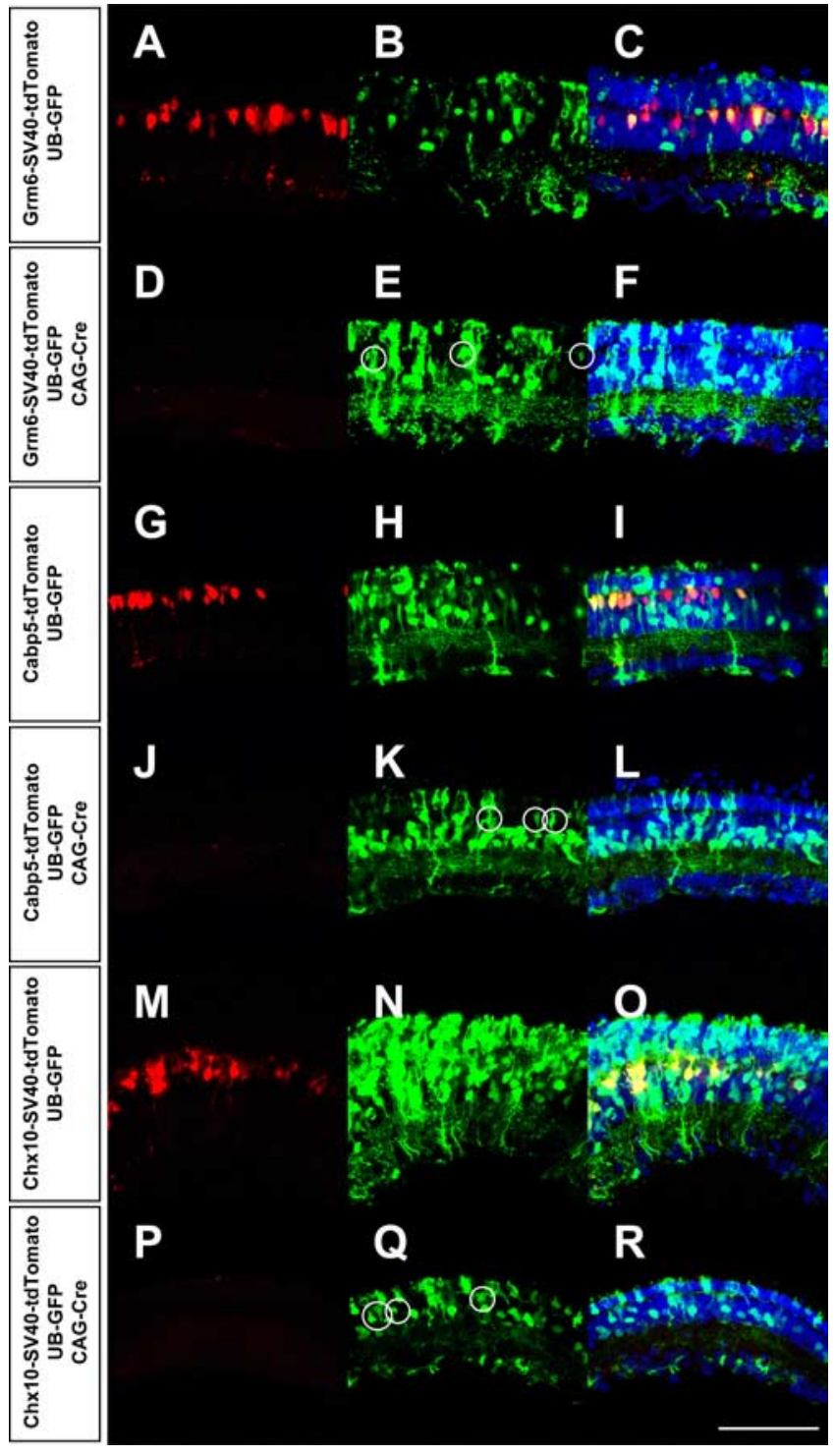

Figure 10. Otx2 conditional loss-of-function analysis. Representative sections from in vivo neonatal retinal transfections of Otx2 ${ }^{\text {floxfflox }}$ mice with UB-GFP, reporter constructs, and CAGCre. Retinas were harvested at P14-P15. A-C, G-I, M-O , Control transfection without CAGCre. $\boldsymbol{D}-\boldsymbol{F}, \boldsymbol{J}-\boldsymbol{L}, \boldsymbol{P}-\boldsymbol{R}, 0$ tx2 conditional loss-of-function resulting from CAG-Cre transfection. $\boldsymbol{B}$, $E, H, K, N, Q, U B-G F P$ transfection. $C, F, I, L, O, R$, Merged images, tdTomato fluorescence (red), GFP fluorescence (green), DAPI staining (blue). $\boldsymbol{A}, \boldsymbol{D}$, The $200 \mathrm{bp}$ Grm6-SV40 promoter-tdTomato transfection. G, J, The 445 bp Cabp5-tdTomato transfection. M, P, The 164 bp Chx10SV40 promoter-tdTomato transfection. Circles, UB-GFP-transfected bipolar cells. Scale bar, $100 \mu \mathrm{m}$.

ing the putative Pou3f2 site or the putative Crx site, suggesting that Brn2, Crx, and Otx 2 can all interact with the Pou3f 2 or Crx site (Fig. 9A). The Brn2 binding activity was of greater molecular weight than that of the CrxMyc and Otx2Myc binding activities, consistent with the relative differences in predicted molecular weights of the Brn2 (47 kDa), CrxMyc (34 $\mathrm{kDa}$ ), and Otx2Myc (33 kDa) proteins (He et al., 1989; Furukawa et al., 1997). Most bands appeared as singlets after gel electrophoresis, but the binding activity in nuclear extracts from cells transfected with the Brn 2 was sometimes present as a doublet, which might reflect Brn2 binding to some tested sites as an oligomer or complexed with other proteins. Western blotting showed that only nuclear extract from cells transfected with Brn2 exhibited immunoreactivity with an anti-

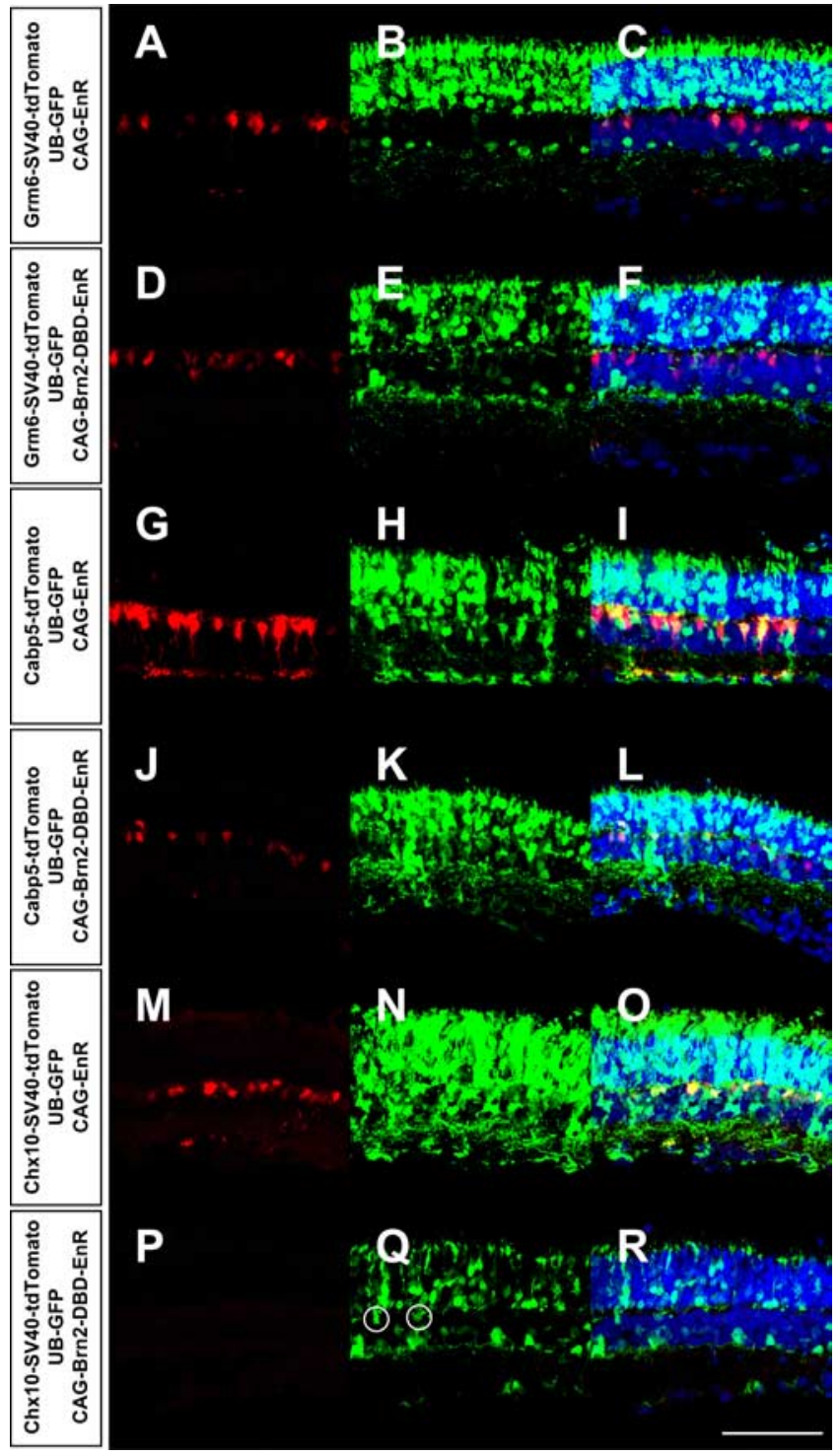

Figure 11. Dominant-negative Brn2 effects. Representative sections from in vivo neonatal mouse retinal transfections of WT mice with UB-GFP, reporter constructs, CAG-EnR, and CAGBrn2-DBD-EnR. Retinas were harvested at P14-P21. A-C, G-I, M-O, CAG-EnR transfection. $D-F, J-L, P-R, C A G-B r n 2-D B D-E n R$ transfection. $B, E, H, K, N, Q, U B-G F P$ transfection. $C, F, I$, $L, \boldsymbol{O}, \boldsymbol{R}$, Merged images, tdTomato fluorescence (red), GFP fluorescence (green), DAPI staining (blue). $A, D$, The 200 bp Grm6-SV40 promoter-tdTomato transfection. $G, J$, The 445 bp Cabp5tdTomato transfection. $\boldsymbol{M}, \boldsymbol{P}$, The 164 bp Chx10-SV40 promoter-tdTomato transfection. Circles, UB-GFP-transfected bipolar cells. Scale bar, $100 \mu \mathrm{m}$.

Brn2 antibody (Fig. 9D). A major band of $\sim 47 \mathrm{kDa}$ and several lower bands, perhaps degradation products, were observed. A similar experiment demonstrated that only nuclear extracts from cells transfected with CrxMyc and Otx2Myc showed immunoreactivity with an anti-Myc antibody (Fig. 9D). CrxMyc and Otx2Myc bands were $\sim 34$ and $\sim 33 \mathrm{kDa}$, respectively. Together, the data suggest that the $200 \mathrm{bp}$ Grm6 CRE contains one relatively specific POU homeodomain-containing TFBS and two sites that can be bound by either POU or paired-type homeodomain-containing TFs (Fig. 9I).

The putative binding sites found in the Cabp5 CRE were also subjected to EMSA analysis. Nuclear extracts from cells transfected with a CrxMyc or Otx2Myc construct contained binding activity that interacted with oligonucleotides containing the Crx or Pitx2 site in the Cabp5 CRE (Fig. 9B). In contrast, nuclear 
A

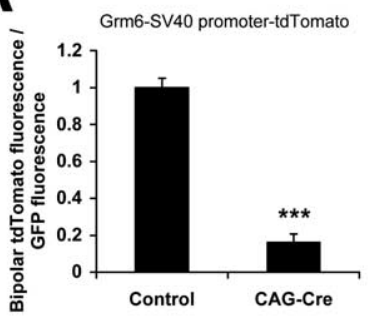

B

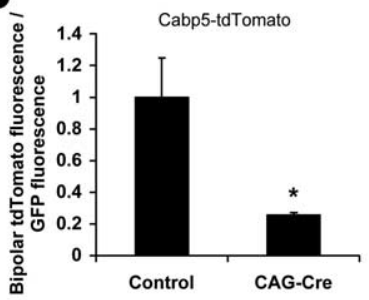

C

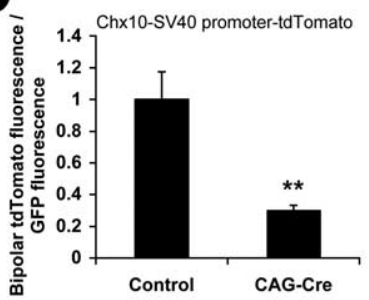

D
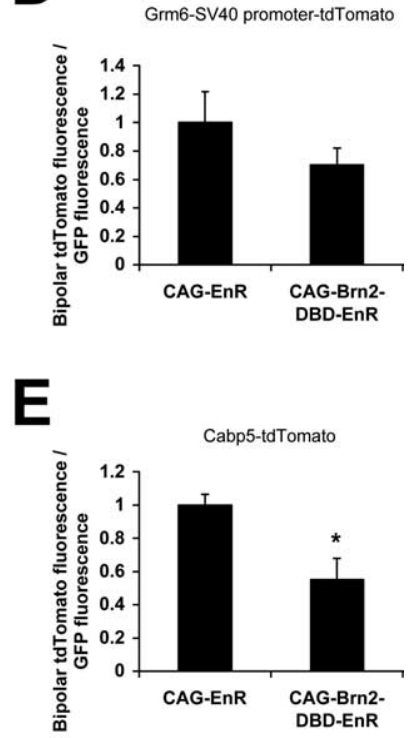

$\mathbf{F}$

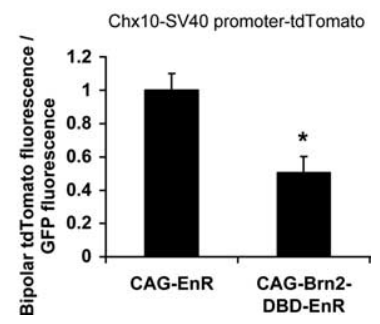

Figure 12. Quantitation of 0tx2 conditional loss-of-function analysis and dominantnegative Brn2 effects. $\boldsymbol{A}, \boldsymbol{D}$, Bipolar cell tdTomato fluorescence to GFP fluorescence ratios for the 200 bp Grm6-SV40 promoter-tdTomato construct. $\boldsymbol{B}, \boldsymbol{E}$, Bipolar cell tdTomato fluorescence to GFP fluorescence ratios for the 445 bp Cabp5-tdTomato construct. C, F, Bipolar cell tdTomato fluorescence to GFP fluorescence ratios for the 164 bp Chx10-SV40 promoter-tdTomato construct. $\boldsymbol{A}-\boldsymbol{C}, 0$ tx $2^{\text {flox/flox }}$ retinas transfected without or with $C A G-C$ re construct. $\boldsymbol{D}-\boldsymbol{F}$, WT retinas transfected with CAG-EnR or CAG-Brn2-DBD-EnR construct. Mean \pm SEM is shown $(n=3$ retinas per construct). Comparison with control or CAG-EnR: ${ }^{*} p<0.05,{ }^{* *} p<0.01,{ }^{* * *} p<$ 0.001 (1-tailed Student's $t$ test).

extract from cells transfected with a Brn2 construct contained binding activity that interacted with oligonucleotides overlapping the $5^{\prime}$ Brn 2 or $3^{\prime}$ Brn 2 site. The results indicate that the 445 bp Cabp5 CRE contains two paired-type homeodomaincontaining TFBSs and two POU homeodomain-containing TFBSs (Fig. 9I).

The putative binding sites identified in the Chx10 CRE were also analyzed using EMSAs. Nuclear extracts from cells transfected with CrxMyc or Otx2Myc contained binding activity that could interact with oligonucleotides overlapping the Crx site in the Chx10 CRE (Fig. 9C). In contrast, nuclear extracts from cell transfected with Brn 2 contained binding activity that could interact with oligonucleotides overlapping the Pou3f2 or Brn2 site. Additionally, nuclear extracts from cells transfected with Brn2 or Otx2Myc contained binding activity that could interact with oligonucleotides overlapping the Otx site. Together, the data suggest that the $164 \mathrm{bp}$ Chx10 CRE contains one relatively specific paired-type homeodomain-containing TFBS, two relatively specific POU homeodomain-containing TFBSs, and one site that can be bound by either POU or paired-type homeodomain-containing TFs (Fig. 9I).

EMSA analysis was also conducted using the same oligonucleotides overlapping identified sites in the Grm6, Cabp5, and Chx10 regulatory sequences and nuclear extracts from adult mouse retinas. Only 7 of 11 sites tested interacted with binding activity in retinal nuclear extract, although low-molecularweight, nonspecific bands could be observed for all probes assayed (Fig. 9F-H). In general, there was an almost complete correlation between presence of binding activity in retinal nuclear extracts and presence of binding activity in cells transfected with CrxMyc (Fig. 9I), suggesting that Crx expressed in photoreceptor cells, which are an abundant cell type in the retina (>70\%) (Young, 1985), could be the factor in native retinal nuclear extracts interacting with these sites. Additionally, in every case except for one putative binding site (Chx10 CRE, Pou3f 2 site), when binding activity was observed only in cells transfected with Brn2 for a given site, no binding activity was detected in nuclear extract from retinas. This suggests that, although Brn 2 can bind to these sites when nuclear extract from transfected cells is used, the in vivo Brn2 expression levels could be too low for binding activity to be detected in EMSAs when nuclear extract from adult mouse retinas is used.

Alignment and comparison of TFBS sequences revealed at least three types of sites with regard to binding activities in transfected cell nuclear extracts. Sites that contained AAAT or GAAT sequences interacted only with binding activities in nuclear extract from cells expressing the POU homeodomain-containing $\mathrm{TF}, \mathrm{Brn} 2$, in almost every case (Fig. 9E). In contrast, sites that contained the core TAAT homeodomain-binding sequence could interact with binding activities in nuclear extracts from cells transfected with paired-type homeodomain-containing TFs, Crx and Otx2, and sometimes also with those in Brn2-transfected cells (Laughon, 1991). Finally, sites that contained a CTAATCC sequence interacted only with binding activities in nuclear extracts from CrxMyc- and Otx2Myc-transfected cells.

\section{Otx2 conditional loss-of-function effects on reporter expression}

Otx2 is highly enriched in its expression in the INL, in which it is found in the majority of bipolar cells of the adult retina (Koike et al., 2007). Previous studies have shown that Otx2 plays a critical role in bipolar cell terminal differentiation (Koike et al., 2007). To test the hypothesis that Otx2 regulates expression of Grm6, Cabp5, and Chx10, reporter expression was examined in control and $O t \times 2$ conditional loss-of-function retinas. Retinas from neonatal Otx $2^{\text {flox/flox }}$ mice were transfected by in vivo electroporation with a plasmid containing the 200 bp Grm6 regulatory element inserted upstream of an SV40 basal promoter and a tdTomato construct as well as with a plasmid with a broadly active promoter driving GFP. Otx2 loss-of-function was achieved by cotransfecting a subset of retinas with reporters and a plasmid containing a broadly active promoter driving Cre recombinase expression. Cotransfected cells, indicated by GFP expression, would be expected to have undergone Cre-mediated deletion of the Otx2 gene. When mature control retinas were examined, tdTomato signal was observed in many transfected bipolar cells (Fig. 10 A), but virtually no tdTomato signal could be seen in $O t \times 2$ conditional knock-out $(\mathrm{CKO})$ retinas, suggesting that $O t \times 2$ is required for activation of this Grm6 regulatory element (Fig. 10D-F). Similarly, the activity of both the 445 bp Cabp5-tdTomato (Fig. $10 \mathrm{~J}-\mathrm{L}$ ) and 164 bp Chx10-SV40 promoter-tdTomato (Fig. $10 P-R)$ reporter constructs was attenuated in Otx2 CKO retinas, despite the presence of cotransfected GFP-positive bipolar cells, suggesting that $O t \times 2$ is also required for activation of the Cabp5 
and Chx10 regulatory elements. These results were quantitated by measuring the ratio of tdTomato fluorescence to GFP fluorescence in bipolar cells (see Fig. 12A-C).

\section{Dominant-negative Brn2 effects on reporter expression}

Brn2 has been demonstrated to be expressed in bipolar cells, among other cell types in the retina (Rowan and Cepko, 2005). To address the hypothesis that Brn2 is required for expression of bipolar cell genes, reporter expression was examined in retinas transfected with a dominantnegative CAG-Brn2-DBD-EnR construct containing the Brn2 DNA binding domain fused to the Drosophila engrailed transcriptional repressor domain. In control experiments, neonatal retinas were transfected with a plasmid containing a broadly active promoter driving the engrailed repressor alone, a plasmid containing the 200 bp Grm6 CRE inserted upstream of an SV40 basal promoter and a tdTomato construct, and a plasmid with a broadly active promoter driving GFP. Examination of mature retinas revealed tdTomato signal in many transfected bipolar cells (Fig. $11 A$ ). The tdTomato signal was similar in bipolar cells from retinas cotransfected with the CAG-Brn2-DBD-EnR construct (Fig. $11 D$ ). In contrast, the tdTomato signal was substantially reduced in bipolar cells from retinas cotransfected with the 445 bp Cabp5-tdTomato and CAG-Brn2DBD-EnR constructs (Fig. 11G-L). Finally, tdTomato signal was reduced to background levels in retinas cotransfected with the 164 bp Chx10-SV40 promotertdTomato and CAG-Brn2-DBD-EnR constructs, despite the presence of cotransfected GFP-positive bipolar cells (Fig. $11 M-R)$. Quantitation of these results is shown in Figure $12 D-F$. The data suggest that recruitment of a transcriptional repressor to Brn2 binding sites can reduce Cabp5 and Chx10 expression.

\section{Otx2 and Crx loss-of-function effects on} endogenous bipolar gene expression

The functional requirement for the paired-type homeodomaincontaining TFs Otx2 and Crx in regulating endogenous gene expression was assayed by RNA in situ hybridization. Retinal sections from WT, Otx $2^{+/-}, \mathrm{Crx}^{-/-}$, and $\mathrm{Ot} \times 2^{+/-} ; \mathrm{Cr} x^{-/-}$mice were examined at $\mathrm{P} 14$ before onset of retinopathy observed in Crx-deficient mice. Otx2-deficient mice were not examined because the forebrain neuroectoderm fails to develop in these embryos, and homozygous null mutations lead to embryonic lethality (Acampora et al., 1995). The hybridization signals for Grm6, Cabp5, and Chx10 were all attenuated in $O t \times 2^{+/-}$retinas (Fig. $\left.13 A^{\prime}, B^{\prime}, C^{\prime}\right)$. The hybridization signals for these genes appeared unaltered in $C r x^{-/-}$retinas (Fig. $13 A^{\prime \prime}, B^{\prime \prime}, C^{\prime}$ ). However, for Grm6, Cabp5, and Chx10, Crx deficiency led to an even greater

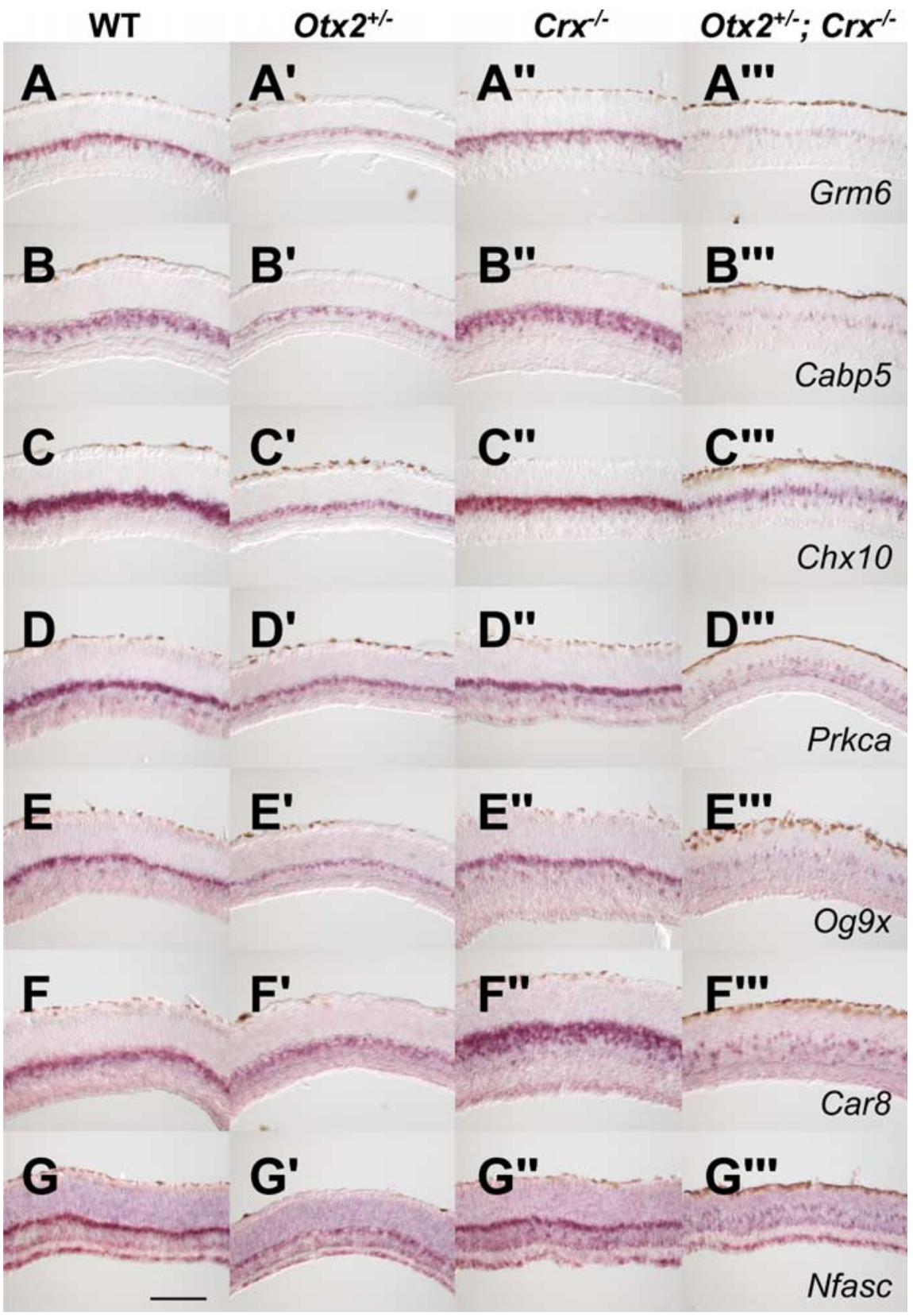

Figure 13. Gene expression patterns in $0 \mathrm{t} \times 2$ and $C r x$ loss-of-function mutant retinas. RNA in situ hybridization patterns from representative sections of $\mathrm{P} 14$ mouse retinas. $A-G$, WT retinal sections. $A^{\prime}-G^{\prime}, O t \times 2^{+/-}$retinal sections. $A^{\prime \prime}-G^{\prime \prime}, C_{r x}{ }^{-/}$retinal

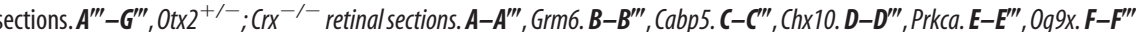
Car8. G-G'", Nfasc. Scale bar, $100 \mu \mathrm{m}$.

attenuation of hybridization signal in the Otx $2^{+/-}$background (Fig. $\left.13 A^{\prime \prime \prime}, B^{\prime \prime \prime}, C^{\prime \prime \prime}\right)$. These results are consistent with a role for Otx2 by itself in activation of Grm6, Cabp5, and Chx10 transcription in bipolar cells and previously described roles for Otx2 together with Crx in bipolar cell genesis and/or survival (Koike et al., 2007; Sato et al., 2007).

To assess to extent of genes potentially regulated by Otx2 and/or Crx, additional bipolar cell markers were examined by RNA in situ hybridization, including the rod bipolar-selective makers Prkca, Og9x, Car8, and Nfasc (Fig. 13D-G'"'), the mixed rod and cone bipolar-selective markers Pcp2, Trpm1, and 2300002D11Rik (Fig. 14A-C'"), and the cone bipolar cell markers Scgn, 6330514A18Rik, and Lhx3 (Fig. 14D-F"') (Kim et al., 2008). The hybridization signals for these genes were all attenuated in 


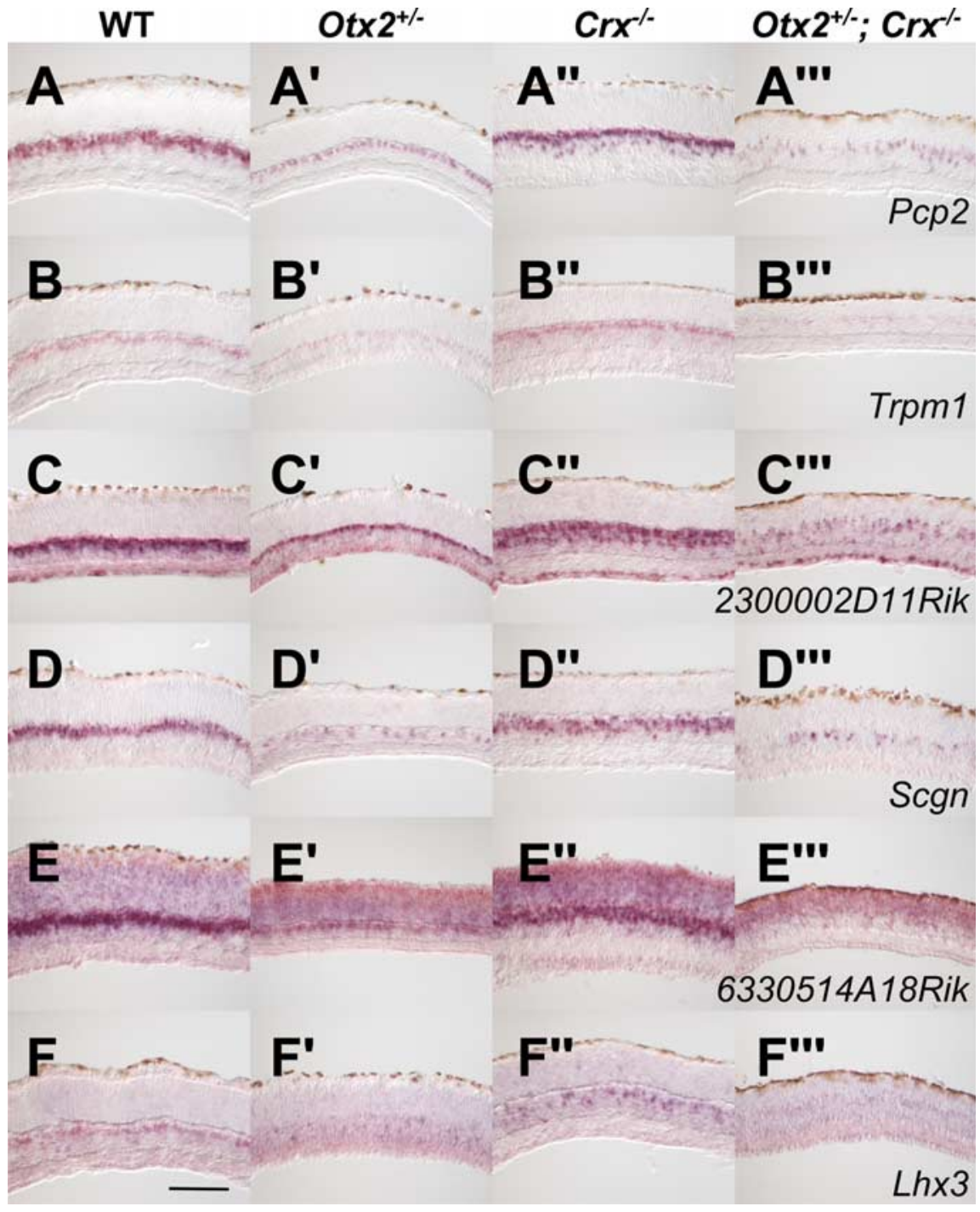

Figure 14. Additional gene expression patterns in 0tx2 and Crx loss-of-function mutant retinas. RNA in situ hybridization patterns from representative sections of P14 mouse retinas. $\boldsymbol{A}-\boldsymbol{F}$, WT retinal sections. $\boldsymbol{A}^{\prime}-\boldsymbol{F}^{\prime}, 0$ tx $2^{+-}$retinal sections. $\boldsymbol{A}^{\prime \prime}-\boldsymbol{F}^{\prime \prime}$, $C r x^{-1-}$ retinal sections. $A^{\prime \prime \prime}-F^{\prime \prime \prime}, 0 t \times 2^{+/-} ; C r x^{-/-}$retinal sections. $A-A^{\prime \prime \prime}, P C p 2 . B-B^{\prime \prime \prime}, \operatorname{Trpm} 1 . C_{-} C^{\prime \prime \prime}, 2300002 D 11 R i k . D-D^{\prime \prime \prime}$, Scgn. $\boldsymbol{E}-\boldsymbol{E}^{\prime \prime \prime}$, 6330514A18Rik. F-F'", Lhx3. Scale bar, $100 \mu \mathrm{m}$.

Ot $x 2^{+/-}$retinas. The hybridization signals for these genes were mostly unchanged in $\mathrm{Crx}^{-/-}$retinas. However, $\mathrm{Cr} x$ deficiency led to an even greater attenuation of hybridization signal in the Ot $x 2^{+/-}$background.

RT-PCR was performed to quantitate the relative expression levels of several genes examined by RNA in situ hybridization. The relative concentrations of real-time PCR products amplified from P14 retinal cDNAs for Grm6, Cabp5, Chx10, Og9x, and Scgn were measured and normalized to those for the ubiquitously expressed gene $\beta$-actin (Actb). For Grm6, $O g 9 x$, and $S c g n$, relative concentrations were markedly reduced in Otx $2^{+/-}$and $O t \times 2^{+/-}$; $C r x^{-1-}$ retinas compared with WT retinas (Fig. $15 A, D, E$ ). For Cabp5 and Chx10, relative concentrations trended downward in $O t \times 2^{+/-}$and $\mathrm{Ot} \times 2^{+/-}$; Crx ${ }^{-/-}$retinas compared with WT retinas, but differences did not reach significance (Fig. 15B, C).

\section{Discussion}

Several lines of evidence suggest that a core set of paired-type and POU homeodomain-containing TFs directly activates transcription of bipolar cell-expressed genes. Regulatory sequences of
$<500$ bp were identified upstream of the mouse Grm6, Cabp5, and Chx10 genes that were capable of driving bipolar cellspecific reporter expression. These sequences each contained predicted pairedtype and POU homeodomain-containing TFBSs, and these sites were shown to be required, individually or in combination, for reporter expression. Sites upstream of each gene were also demonstrated to be able to interact with the POU homeodomaincontaining $\mathrm{TF}$ Brn2 and the paired-type homeodomain-containing TFs Crx and Otx2. Conditional inactivation of Otx 2 led to loss of reporter expression, and dominantnegative Brn2-DBD-EnR expression reduced activity of two reporters. Endogenous Grm6, Cabp5, and Chx10 expression appeared reduced in $O t \times 2^{+/-}$mutant retinas, and the expression of or the number of cells transcribing these genes also appeared further reduced in $\mathrm{Ot} x 2^{+/-}$; $\mathrm{Cr} x^{-/-}$retinas. Similar results were obtained for other bipolar cell-enriched genes, perhaps indicating the general importance of these paired-type homeodomain-containing TFs in bipolar cell gene expression.

It is possible that other TFs interact with the identified CREs. Evaluation of the importance of the predicted paired-type and POU homeodomain-containing TFBSs was based primarily on recognition of these putative sites by a limited database of TFBS matrices of varying information content. However, even using this limited set, occurrence of binding sites for these TF families was selective in that, for example, no putative LIM homeobox TFBSs were found, despite representation in the database. Moreover, binding sites that were represented for other paired-type homeodomain-containing TFs, such as Chx10, were not observed. Even the sites identified using the limited database might be bound by related TFs other than Brn2, Crx, and Otx2, such as the bipolar cell-expressed TFs Chx10, Vsx1, and Og9x (Liu et al., 1994; Burmeister et al., 1996; Chow et al., 2001; Kim et al., 2008). More exhaustive EMSA analysis could aid in identifying other interacting TFs. However, none of these related TFs except Chx10 is expressed in as many bipolar cells as Otx2 (Koike et al., 2007), and thus activation of at least the pan-bipolar cell gene Chx10 would have to depend on several proteins. It is also possible that CREs other than those isolated in this study regulate Grm6, Cabp5, and Chx10 expression. Indeed, a proximal Chx10 CRE has been characterized containing sequences directing dividing progenitor and bipolar cell expression that can be bound by Brn2 (Rowan and Cepko, 2005). The novel isolated Chx10 and Grm6 regulatory elements are positioned 19 and $8 \mathrm{~kb}$ upstream of transcriptional start sites, respectively. Other regulatory elements in the vicinity of Grm6, Cabp5, and Chx10 could exist and contain sites for TFs not discussed here.

Consistent with a role for Otx 2 in transcription of the bipolar cell genes Grm6, Cabp5, and Chx10 reporter activity for these 

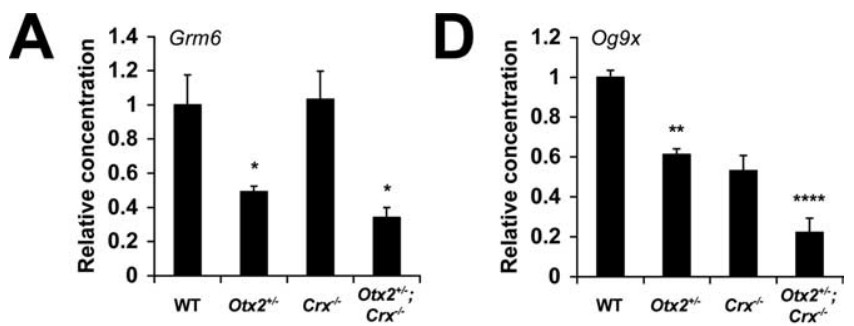

B
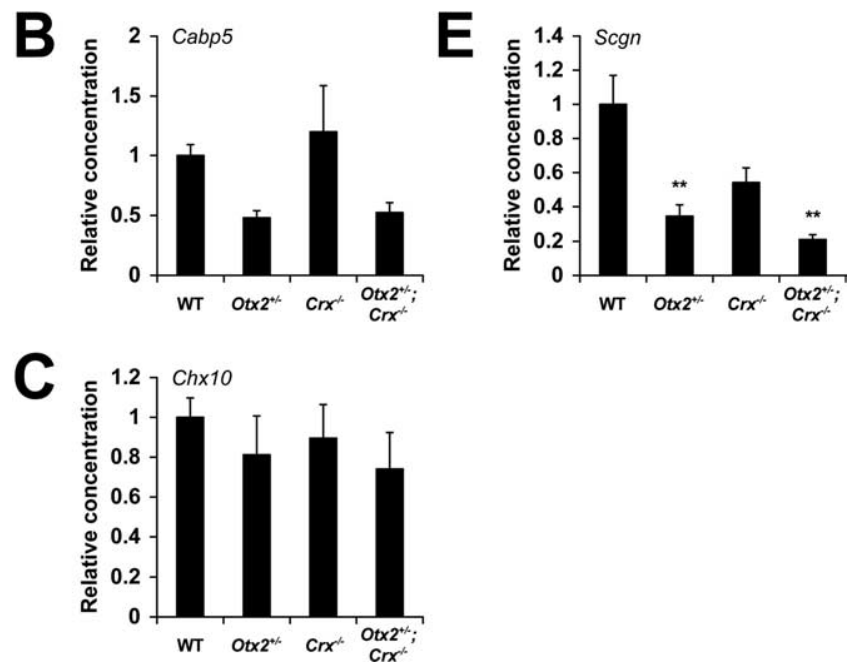

Figure 15. Quantitation of relative gene expression levels by RT-PCR in 0tx2 and Crx loss-of-function mutant retinas. Relative concentrations of real-time $P C R$ products for several genes each normalized to $\beta$-actin $(A c t b)$ concentrations from P14 WT, Otx2 ${ }^{+/-}$, $\mathrm{Crx}^{-1-}$, and Otx2 ${ }^{+/-} ; \mathrm{Crx}^{-1-}$ mouse retinas are shown. A, Grm6. B, Cabp5. C, Chx10. D, $0 \mathrm{~g} 9 \mathrm{x} . \boldsymbol{E}, \mathrm{Scgn}$. Mean \pm SEM is shown ( $n=3$ retinas per genotype). Comparison with WT: ${ }^{*} p<0.05,{ }^{* *} p<0.01,{ }^{* * *} p<0.0001$ (1-way ANOVA and 1-tailed Tukey's post hoc test).

genes and their endogenous expression levels appeared attenuated in Otx $2 \mathrm{CKO}$ and $\mathrm{Ot} \times 2^{+/-}$retinas. In contrast, a previous analysis found that $O t \times 2^{+/-}$mutants exhibit normal Chx10 retinal expression, as assessed by antibody staining (Koike et al., 2007). Differences in RNA in situ hybridization versus immunohistochemical results could reflect uncharacterized translational control and/or protein stability of Chx10. Furthermore, it is possible that apparent reduction of Grm6, Cabp5, and Chx10 reporter activity and endogenous expression levels reflects decreases in bipolar cell numbers in Otx $2^{+/-}$and Otx2 CKO retinas through effects on bipolar cell genesis or survival. However, previous analysis showed that $O t \times 2^{+/-}$retinas did not exhibit elevated cell death during retinogenesis (Koike et al., 2007). Additionally, Otx2 CKO retinas that were transfected with Cre exhibited virtually no Grm6, Cabp5, or Chx10 reporter activity, but cotransfected GFP-positive bipolar cells identified based on position and cell body morphology were still evident. Thus, although some bipolar cell death might have resulted from reduction of Otx2 function, Grm6, Cabp5, and Chx10 gene expression depends partially on Otx2, and this TF likely directly activates transcription of these genes. Otx $2^{+/-} ; \mathrm{Crx}^{-/-}$mutant retinas were shown to exhibit elevated cell death, and so it is unclear whether additional attenuation of hybridization signals for bipolar cell markers reflects a role for Crx in regulating bipolar cell genes and/or promoting survival in the Otx $2^{+/-}$mutant background (Koike et al., 2007).

The results also suggest that multiple regulatory elements for Chx10 exist for control of gene expression timing and/or cell-type specificity. The distal 164 bp Chx10 CRE drove fluorescent or AP reporter expression in bipolar cells relatively late during retinogenesis but did not activate detectable fluorescent reporter expression in progenitor cells. In contrast, the previously characterized, proximal $C h \times 10$ CRE is sufficient for AP reporter expression in bipolar cells and progenitor cells in transgenic mice (Rowan and Cepko, 2005). The role of the distal 164 bp Chx10 CRE might thus be to increase $C h \times 10$ transcription at a time when bipolar cells first appear and/or thereafter. In this regard, it is interesting that both regulatory elements contain Brn2 binding sites critical for reporter expression, although a requirement for Brn2 function has been tested only for the distal 164 bp CRE using the dominant-negative Brn 2 construct. Late activity of the distal 164 bp Chx10 CRE might result from the persistence of high levels of Otx 2 only in developing bipolar cells (Baas et al., 2000; Koike et al., 2007). It was not possible to address whether Otx2 regulates the proximal CRE using electroporation because, surprisingly, this promoter was not active in transfected retinas (data not shown). The proximal CRE was active in transgenic mice, which might indicate differences attributable to integration or other aspects of DNA regulation associated with transgenesis (Rowan and Cepko, 2005).

Because Chx10 is necessary and sufficient for bipolar cell fate determination (Burmeister et al., 1996; Green et al., 2003; LivneBar et al., 2006), it could be speculated that Otx2 could drive bipolar cell fate determination by activating the distal $164 \mathrm{bp}$ Chx10 CRE and increasing Chx10 expression beyond levels found in progenitor cells. This notion, coupled with results consistent with a role for Otx2 in directly activating transcription of differentiation genes, such as Grm6 and Cabp5, as well as Prkca (Koike et al., 2007), raises the possibility that Otx2 regulates both early bipolar cell fate determination genes and late differentiation genes in a relatively simple transcriptional hierarchy. An alternative possibility to direct regulation of early and late bipolar cell genes by Otx 2 is that it could activate Chx10 expression, and Chx10 could then activate transcription of late differentiation genes, such as Grm6 and Cabp5. Chx10 has been shown to function as a transcriptional repressor, and so putative Chx10 activation of bipolar cell genes would be expected to be indirect or reflect a dual ability to repress and activate in different contexts (Dorval et al., 2005, 2006; Livne-Bar et al., 2006).

The results also suggest that paired-type and POU homeodomain-containing TFs could act together to drive bipolar cell gene expression. Isolated regulatory elements were sensitive to deletions of binding sites for both paired-type and POU homeodomain-containing TFs. This suggests that action by TFs from these families is critical in driving transcription at least for these elements. Joint action of paired-type and POU homeodomain-containing TFs might aid in refining spatial and/or temporal expression. It might also provide quantitative control. For instance, it is apparent that, whereas in Otx2 CKO and CAG-Brn2-DBD-EnR-transfected retinas the 164 bp Chx10 reporter expression decreased, some endogenous Chx10 expression persisted above the threshold necessary for bipolar cell development because transfected bipolar cells, identified based on position and cell body morphology, were still present. Although Otx2 and Brn2 are important for Chx10, Grm6, and Cabp5 expression, each is not sufficient because many cells contain these TFs but do not express these genes. For example, Otx2 is expressed throughout the developing forebrain, in the optic vesicle, in developing photoreceptor cells, and in the retinal pigmented epithelium (Acampora et al., 1995; Koike et al., 2007). Brn2 is found in the developing cortex and many early retinal progenitor 
cells (Sugitani et al., 2002; Rowan and Cepko, 2005). Additionally, in the developing neonatal rat retina, Otx2 misexpression led to greater photoreceptor cell production (Nishida et al., 2003). Other investigators found that XOtx2 misexpression in the developing Xenopus retina can promote the bipolar cell fate (Viczian et al., 2003).

The results have shed light on the core TFs important in driving expression of several bipolar cell genes. Determining TFs directing expression of Grm6, Cabp5, and Chx10 in different bipolar cell subtypes will be the subject of future studies. Differentially expressed TFs that are critical for bipolar cell development and maintenance, such as Vsx1, Isl1, Irx5, Bhlhb4, and Bhlhb5, could work in concert with Otx2 and/or Brn2 to shape bipolar cell subtype gene expression (Bramblett et al., 2004; Chow et al., 2004; Ohtoshi et al., 2004; Cheng et al., 2005; Feng et al., 2006; Clark et al., 2007; Elshatory et al., 2007). Additionally, genomic sequences from other genes sufficient for specific bipolar cell expression have been identified previously (Oberdick et al., 1990; Wong et al., 1999). Unbiased screening methods for CREs described here will be used to isolate elements from these and other bipolar cell genes. Screening using a functional criterion was advantageous compared with relying on a conserved sequencebased approach because many conserved sequences turned out to be dispensable for bipolar cell expression. These and future functional analyses of gene regulation will shed greater light on neuronal development and function at the level of molecular and gene networks. Electroporation of constructs containing relatively short CREs inserted upstream of fluorescent reporters, transynaptic tracing molecules, toxins, or activity-altering ion channels (Lagali et al., 2008) have been shown previously and will prove to be useful for more precise retinal circuitry mapping, physiological studies, and cell-type-specific gene therapy using viral vectors.

\section{References}

Acampora D, Mazan S, Lallemand Y, Avantaggiato V, Maury M, Simeone A, Brûlet P (1995) Forebrain and midbrain regions are deleted in Otx2-1- mutants due to a defective anterior neuroectoderm specification during gastrulation. Development 121:3279-3290.

Akagi T, Inoue T, Miyoshi G, Bessho Y, Takahashi M, Lee JE, Guillemot F, Kageyama R (2004) Requirement of multiple basic helix-loop-helix genes for retinal neuronal subtype specification. J Biol Chem 279:28492-28498.

Baas D, Bumsted KM, Martinez JA, Vaccarino FM, Wikler KC, Barnstable CJ (2000) The subcellular localization of Otx2 is cell-type specific and developmentally regulated in the mouse retina. Brain Res Mol Brain Res 78:26-37.

Berrebi AS, Oberdick J, Sangameswaran L, Christakos S, Morgan JI, Mugnaini E (1991) Cerebellar Purkinje cell markers are expressed in retinal bipolar neurons. J Comp Neurol 308:630-649.

Blackshaw S, Harpavat S, Trimarchi J, Cai L, Huang H, Kuo WP, Weber G, Lee K, Fraioli RE, Cho SH, Yung R, Asch E, Ohno-Machado L, Wong WH, Cepko CL (2004) Genomic analysis of mouse retinal development. PLoS Biol 2:E247.

Bramblett DE, Pennesi ME, Wu SM, Tsai MJ (2004) The transcription factor Bhlhb4 is required for rod bipolar cell maturation. Neuron 43:779-793.

Burmeister M, Novak J, Liang MY, Basu S, Ploder L, Hawes NL, Vidgen D, Hoover F, Goldman D, Kalnins VI, Roderick TH, Taylor BA, Hankin MH, McInnes RR (1996) Ocular retardation mouse caused by Chx10 homeobox null allele: impaired retinal progenitor proliferation and bipolar cell differentiation. Nat Genet 12:376-384.

Chen S, Wang QL, Nie Z, Sun H, Lennon G, Copeland NG, Gilbert DJ, Jenkins NA, Zack DJ (1997) Crx, a novel Otx-like paired-homeodomain protein, binds to and transactivates photoreceptor cell-specific genes. Neuron 19:1017-1030.

Cheng CW, Chow RL, Lebel M, Sakuma R, Cheung HO, Thanabalasingham
V, Zhang X, Bruneau BG, Birch DG, Hui CC, McInnes RR, Cheng SH (2005) The Iroquois homeobox gene, Irx5, is required for retinal cone bipolar cell development. Dev Biol 287:48-60.

Chow RL, Snow B, Novak J, Looser J, Freund C, Vidgen D, Ploder L, McInnes RR (2001) Vsxl, a rapidly evolving paired-like homeobox gene expressed in cone bipolar cells. Mech Dev 109:315-322.

Chow RL, Volgyi B, Szilard RK, Ng D, McKerlie C, Bloomfield SA, Birch DG, McInnes RR (2004) Control of late off-center cone bipolar cell differentiation and visual signaling by the homeobox gene Vsxl. Proc Natl Acad Sci USA 101:1754-1759.

Clark AM, Yun S, Veien ES, Wu YY, Chow RL, Dorsky RI, Levine EM (2007) Negative regulation of Vsx1 by its paralog Chx10/Vsx2 is conserved in the vertebrate retina. Brain Res 1192:99-113.

Conlon FL, Sedgwick SG, Weston KM, Smith JC (1996) Inhibition of Xbra transcription activation causes defects in mesodermal patterning and reveals autoregulation of Xbra in dorsal mesoderm. Development 122:2427-2435

de Melo J, Qiu X, Du G, Cristante L, Eisenstat DD (2003) Dlx1, Dlx2, Pax6, $\mathrm{Brn} 3 \mathrm{~b}$, and Chx 10 homeobox gene expression defines the retinal ganglion and inner nuclear layers of the developing and adult mouse retina. J Comp Neurol 461:187-204.

Dorval KM, Bobechko BP, Ahmad KF, Bremner R (2005) Transcriptional activity of the paired-like homeodomain proteins CHX10 and VSX1. J Biol Chem 280:10100-10108.

Dorval KM, Bobechko BP, Fujieda H, Chen S, Zack DJ, Bremner R (2006) CHX10 targets a subset of photoreceptor genes. J Biol Chem 281:744-751.

Dyer MA, Cepko CL (2000) Control of Müller glial cell proliferation and activation following retinal injury. Nat Neurosci 3:873-880.

Elshatory Y, Everhart D, Deng M, Xie X, Barlow RB, Gan L (2007) Islet-1 controls the differentiation of retinal bipolar and cholinergic amacrine cells. J Neurosci 27:12707-12720.

Euler T, Wässle H (1995) Immunocytochemical identification of cone bipolar cells in the rat retina. J Comp Neurol 361:461-478.

Feng L, Xie X, Joshi PS, Yang Z, Shibasaki K, Chow RL, Gan L (2006) Requirement for Bhlhb5 in the specification of amacrine and cone bipolar subtypes in mouse retina. Development 133:4815-4825.

Fields-Berry SC, Halliday AL, Cepko CL (1992) A recombinant retrovirus encoding alkaline phosphatase confirms clonal boundary assignment in lineage analysis of murine retina. Proc Natl Acad Sci USA 89:693-697.

Fletcher EL, Koulen P, Wässle H (1998) GABAA and GABAC receptors on mammalian rod bipolar cells. J Comp Neurol 396:351-365.

Furukawa A, Koike C, Lippincott P, Cepko CL, Furukawa T (2002) The mouse Crx $5^{\prime}$-upstream transgene sequence directs cell-specific and developmentally regulated expression in retinal photoreceptor cells. J Neurosci 22:1640-1647.

Furukawa T, Morrow EM, Cepko CL (1997) Crx, a novel otx-like homeobox gene, shows photoreceptor-specific expression and regulates photoreceptor differentiation. Cell 91:531-541.

Furukawa T, Morrow EM, Li T, Davis FC, Cepko CL (1999) Retinopathy and attenuated circadian entrainment in Crx-deficient mice. Nat Genet 23:466-470.

Ghosh KK, Bujan S, Haverkamp S, Feigenspan A, Wässle H (2004) Types of bipolar cells in the mouse retina. J Comp Neurol 469:70-82.

Gray PA, Fu H, Luo P, Zhao Q, Yu J, Ferrari A, Tenzen T, Yuk DI, Tsung EF, Cai Z, Alberta JA, Cheng LP, Liu Y, Stenman JM, Valerius MT, Billings N, Kim HA, Greenberg ME, McMahon AP, Rowitch DH, Stiles CD, Ma Q (2004) Mouse brain organization revealed through direct genome-scale transcription factor expression analysis. Science 306:2255-2257.

Green ES, Stubbs JL, Levine EM (2003) Genetic rescue of cell number in a mouse model of microphthalmia: interactions between Chx10 and G1phase cell cycle regulators. Development 130:539-552.

Greferath U, Grünert U, Wässle H (1990) Rod bipolar cells in the mammalian retina show protein kinase C-like immunoreactivity. J Comp Neurol 301:433-442.

Haeseleer F, Sokal I, Verlinde CL, Erdjument-Bromage H, Tempst P, Pronin AN, Benovic JL, Fariss RN, Palczewski K (2000) Five members of a novel $\mathrm{Ca}^{2+}$-binding protein (CABP) subfamily with similarity to calmodulin. J Biol Chem 275:1247-1260.

Haverkamp S, Ghosh KK, Hirano AA, Wässle H (2003a) Immunocytochemical description of five bipolar cell types of the mouse retina. J Comp Neurol 455:463-476. 
Haverkamp S, Haeseleer F, Hendrickson A (2003b) A comparison of immunocytochemical markers to identify bipolar cell types in human and monkey retina. Vis Neurosci 20:589-600.

He X, Treacy MN, Simmons DM, Ingraham HA, Swanson LW, Rosenfeld MG (1989) Expression of a large family of POU-domain regulatory genes in mammalian brain development. Nature 340:35-41.

Huang L, Max M, Margolskee RF, Su H, Masland RH, Euler T (2003) G protein subunit $\mathrm{G}$ gamma 13 is coexpressed with $\mathrm{G}$ alpha o, $\mathrm{G}$ beta 3, and G beta 4 in retinal ON bipolar cells. J Comp Neurol 455:1-10.

Karolchik D, Baertsch R, Diekhans M, Furey TS, Hinrichs A, Lu YT, Roskin KM, Schwartz M, Sugnet CW, Thomas DJ, Weber RJ, Haussler D, Kent WJ; University of California Santa Cruz (2003) The UCSC Genome Browser Database. Nucleic Acids Res 31:51-54.

Kent WJ, Sugnet CW, Furey TS, Roskin KM, Pringle TH, Zahler AM, Haussler D (2002) The human genome browser at UCSC. Genome Res 12:996-1006.

Kim DS, Ross SE, Trimarchi JM, Aach J, Greenberg ME, Cepko CL (2008) Identification of molecular markers of bipolar cells in the murine retina. J Comp Neurol 507:1795-1810.

Koike C, Nishida A, Ueno S, Saito H, Sanuki R, Sato S, Furukawa A, Aizawa S, Matsuo I, Suzuki N, Kondo M, Furukawa T (2007) Functional roles of Otx2 transcription factor in postnatal mouse retinal development. Mol Cell Biol 27:8318-8329.

Koulen P, Brandstätter JH, Enz R, Bormann J, Wässle H (1998) Synaptic clustering of $\mathrm{GABA}(\mathrm{C})$ receptor rho-subunits in the rat retina. Eur J Neurosci 10:115-127.

Lagali PS, Balya D, Awatramani GB, Münch TA, Kim DS, Busskamp V, Cepko CL, Roska B (2008) Light-activated channels targeted to ON bipolar cells restore visual function in retinal degeneration. Nat Neurosci 11:667-675.

Larkin MA, Blackshields G, Brown NP, Chenna R, McGettigan PA, McWilliam H, Valentin F, Wallace IM, Wilm A, Lopez R, Thompson JD, Gibson TJ, Higgins DG (2007) Clustal W and Clustal X version 2.0. Bioinformatics 23:2947-2948.

Laughon A (1991) DNA binding specificity of homeodomains. Biochemistry 30:11357-11367.

Lewandoski M, Meyers EN, Martin GR (1997) Analysis of Fgf8 gene function in vertebrate development. Cold Spring Harb Symp Quant Biol 62:159-168.

Liu IS, Chen JD, Ploder L, Vidgen D, van der Kooy D, Kalnins VI, McInnes RR (1994) Developmental expression of a novel murine homeobox gene (Chx10): evidence for roles in determination of the neuroretina and inner nuclear layer. Neuron 13:377-393.

Livne-Bar I, Pacal M, Cheung MC, Hankin M, Trogadis J, Chen D, Dorval KM, Bremner R (2006) Chx10 is required to block photoreceptor differentiation but is dispensable for progenitor proliferation in the postnatal retina. Proc Natl Acad Sci USA 103:4988-4993.

Loots GG, Ovcharenko I (2004) rVISTA 2.0: evolutionary analysis of transcription factor binding sites. Nucleic Acids Res 32:W217-W221.

Matsuda T, Cepko CL (2004) Electroporation and RNA interference in the rodent retina in vivo and in vitro. Proc Natl Acad Sci USA 101:16-22.

Matsuda T, Cepko CL (2007) Controlled expression of transgenes introduced by in vivo electroporation. Proc Natl Acad Sci USA 104:1027-1032.

Matys V, Kel-Margoulis OV, Fricke E, Liebich I, Land S, Barre-Dirrie A, Reuter I, Chekmenev D, Krull M, Hornischer K, Voss N, Stegmaier P, Lewicki-Potapov B, Saxel H, Kel AE, Wingender E (2006) TRANSFAC and its module TRANSCompel: transcriptional gene regulation in eukaryotes. Nucleic Acids Res 34:D108-D110.

Morrow EM, Chen CM, Cepko CL (2008) Temporal order of bipolar cell genesis in the neural retina. Neural Develop 3:2.

Murtaugh LC, Chyung JH, Lassar AB (1999) Sonic hedgehog promotes somitic chondrogenesis by altering the cellular response to BMP signaling. Genes Dev 13:225-237.

Nakajima Y, Iwakabe H, Akazawa C, Nawa H, Shigemoto R, Mizuno N, Nakanishi S (1993) Molecular characterization of a novel retinal metabotropic glutamate receptor mGluR6 with a high agonist selectivity for L-2-amino-4-phosphonobutyrate. J Biol Chem 268:11868-11873.

Nishida A, Furukawa A, Koike C, Tano Y, Aizawa S, Matsuo I, Furukawa T (2003) Otx2 homeobox gene controls retinal photoreceptor cell fate and pineal gland development. Nat Neurosci 6:1255-1263.

Oberdick J, Smeyne RJ, Mann JR, Zackson S, Morgan JI (1990) A promoter that drives transgene expression in cerebellar Purkinje and retinal bipolar neurons. Science 248:223-226.

Ohtoshi A, Justice MJ, Behringer RR (2001) Isolation and characterization of Vsxl, a novel mouse CVC paired-like homeobox gene expressed during embryogenesis and in the retina. Biochem Biophys Res Commun 286:133-140.

Ohtoshi A, Wang SW, Maeda H, Saszik SM, Frishman LJ, Klein WH, Behringer RR (2004) Regulation of retinal cone bipolar cell differentiation and photopic vision by the CVC homeobox gene Vsx1. Curr Biol 14:530536.

Ovcharenko I, Loots GG, Hardison RC, Miller W, Stubbs L (2004) zPicture: dynamic alignment and visualization tool for analyzing conservation profiles. Genome Res 14:472-477.

Pignatelli V, Strettoi E (2004) Bipolar cells of the mouse retina: a gene gun, morphological study. J Comp Neurol 476:254-266.

Rowan S, Cepko CL (2004) Genetic analysis of the homeodomain transcription factor Chx10 in the retina using a novel multifunctional BAC transgenic mouse reporter. Dev Biol 271:388-402.

Rowan S, Cepko CL (2005) A POU factor binding site upstream of the Chx10 homeobox gene is required for Chx10 expression in subsets of retinal progenitor cells and bipolar cells. Dev Biol 281:240-255.

Sato S, Inoue T, Terada K, Matsuo I, Aizawa S, Tano Y, Fujikado T, Furukawa T (2007) Dkk3-Cre BAC transgenic mouse line: a tool for highly efficient gene deletion in retinal progenitor cells. Genesis 45:502-507.

Shaner NC, Campbell RE, Steinbach PA, Giepmans BN, Palmer AE, Tsien RY (2004) Improved monomeric red, orange and yellow fluorescent proteins derived from Discosoma sp. red fluorescent protein. Nat Biotechnol 22:1567-1572.

Siepel A, Bejerano G, Pedersen JS, Hinrichs AS, Hou M, Rosenbloom K, Clawson H, Spieth J, Hillier LW, Richards S, Weinstock GM, Wilson RK, Gibbs RA, Kent WJ, Miller W, Haussler D (2005) Evolutionarily conserved elements in vertebrate, insect, worm, and yeast genomes. Genome Res 15:1034-1050.

Sugitani Y, Nakai S, Minowa O, Nishi M, Jishage K, Kawano H, Mori K, Ogawa M, Noda T (2002) Brn-1 and Brn-2 share crucial roles in the production and positioning of mouse neocortical neurons. Genes Dev 16:1760-1765.

Takebayashi K, Takahashi S, Yokota C, Tsuda H, Nakanishi S, Asashima M, Kageyama R (1997) Conversion of ectoderm into a neural fate by ATH-3, a vertebrate basic helix-loop-helix gene homologous to Drosophila proneural gene atonal. EMBO J 16:384-395.

Tian E, Kimura C, Takeda N, Aizawa S, Matsuo I (2002) Otx2 is required to respond to signals from anterior neural ridge for forebrain specification. Dev Biol 242:204-223.

Tomita K, Moriyoshi K, Nakanishi S, Guillemot F, Kageyama R (2000) Mammalian achaete-scute and atonal homologs regulate neuronal versus glial fate determination in the central nervous system. EMBO J 19:5460-5472.

Trimarchi JM, Stadler MB, Roska B, Billings N, Sun B, Bartch B, Cepko CL (2007) Molecular heterogeneity of developing retinal ganglion and amacrine cells revealed through single cell gene expression profiling. J Comp Neurol 502:1047-1065.

Trimarchi JM, Stadler MB, Cepko CL (2008) Individual retinal progenitor cells display extensive heterogeneity of gene expression. PLoS ONE 3:e1588.

Ueda Y, Iwakabe H, Masu M, Suzuki M, Nakanishi S (1997) The mGluR6 5' upstream transgene sequence directs a cell-specific and developmentally regulated expression in retinal rod and ON-type cone bipolar cells. J Neurosci 17:3014-3023.

Vardi N (1998) Alpha subunit of Go localizes in the dendritic tips of ON bipolar cells. J Comp Neurol 395:43-52.

Vardi N, Morigiwa K (1997) ON cone bipolar cells in rat express the metabotropic receptor mGluR6. Vis Neurosci 14:789-794.

Viczian AS, Vignali R, Zuber ME, Barsacchi G, Harris WA (2003) XOtx5b and XOtx2 regulate photoreceptor and bipolar fates in the Xenopus retina. Development 130:1281-1294.

Wong GT, Ruiz-Avila L, Margolskee RF (1999) Directing gene expression to gustducin-positive taste receptor cells. J Neurosci 19:5802-5809.

Young RW (1985) Cell differentiation in the retina of the mouse. Anat Rec 212:199-205. 